\title{
Response of grease film at low speeds under pure rolling reciprocating motion
}

\author{
Yiming HAN ${ }^{1}$, Jing WANG ${ }^{1,}$, Shanshan WANG ${ }^{1}$, Qian ZOU $^{2}$, Gary BARBER ${ }^{2}$ \\ ${ }^{1}$ School of Mechanical and Automotive Engineering, Qingdao University of Technology, Huangdao Campus, Qingdao 266520, China \\ ${ }^{2}$ School of Engineering and Computer Science, Oakland University, Rochester, MI 48309, USA \\ Received: 30 March 2018 / Revised: 9 August 2018 / Accepted: 30 September 2018 \\ (C) The author(s) 2018. This article is published with open access at Springerlink.com
}

\begin{abstract}
Using an optical interferometric technique, the grease film distribution under a pure rolling reciprocating motion is observed on a ball-disk test rig, to explore the transient response of grease, which is expected to fill the contact with thickener fiber and run for a long time under steady-state conditions. It is found that the reciprocating motion reduces the accumulation of the thickener fiber gradually with time. The maximum film thickness forms around the stroke ends. After 1,000 working cycles, very severe starvation occurs so that either the central or minimum film thickness becomes nearly constant over one working period. Thus, the life of grease lubrication under a transient condition is far below that under steady-state conditions. However, it is also found that by selecting a smaller stroke length, the thickener fiber spreads out in the contact instead of being removed from the contact at the 1,000th working period. When increasing the maximum entraining speed of the reciprocating motion to a certain value, during which the thickener fiber is not expected to accumulate under a steady-state condition, severe starvation occurs very quickly, causing surface damage.
\end{abstract}

Keywords: grease lubrication; reciprocation; pure rolling; grease starvation; thickener fiber

\section{Introduction}

In industrial applications, many key components such as gears, chain drives, and rolling element bearings work under a transient state. As an important branch of transient elastohydrodynamic lubrication (EHL), reciprocation is a common form of motion. Over the last 50 years, many researchers [1-6] have explored the oil film characteristics of reciprocating motion by experimental and theoretical methods.

However, $90 \%$ of rolling element bearings, some gears, and chain drives are lubricated with grease. The thickener fiber existing in the grease forms a complex network structure in order to store oil, offering grease a superior advantage over oil lubrication. Because of the complex structure of grease, the influence of grease thickener fiber on lubrication has become an important issue in recent years.

Li et al. [7] conducted an experimental investigation to explore crescent-shaped grease film in rolling and sliding microoscillation. They [8] also observed the transient grease film variation in a reciprocating motion during one working cycle. Wang et al. [9] studied the grease film distribution in a reciprocating sliding motion experimentally on a ball-disk test rig using an optical interferometric technique. They found that the grease film in a reciprocating motion exhibited different features than that of oil lubrication.

In the first several working periods, the variations of the film shape in the first and second strokes are different. With an increase of the period number, the starvation effect gradually emerges, together with the occurrence of grease replenishment. After a large number of working periods, very severe grease

* Corresponding author: Jing WANG, E-mail: wj20011226@163.com 
starvation occurs so that the central and minimum film thicknesses are thin and constant over a working period.

Many studies on grease were based on steady-state conditions. Ali et al. [10] added shrapnel to a ball-disc test rig, pushing the grease back to the track in order to study the lubrication replenishment of the grease. Huang et al. [11] showed that the slide/roll ratio contributed to replenishing the contact by transferring more grease to the vicinity of the contact to form a larger lubricant reservoir.

Eriksson et al. [12] monitored the status of the ball-disk contact area and observed directly that the thickener fiber entered and passed through the contact area, resulting in fluctuations in the thickness of the grease film. Cann et al. [13] detected the thickener fiber through infrared reflectance spectroscopy technology in both the inlet and the outlet of the contact zone. This showed that the grease fiber has an oil storage function and participates in the lubrication together with the oil.

Cyriac et al. [14] experimentally explored the influence of the thickener particle size and concentration on the grease EHL film thickness, and found that the film thickness increases with an increase in the particle size and concentration at medium speed. For the lowspeed condition, Zhang [15] explored the lubrication characteristics of lithium grease mixed with glycerinum in point contacts. She also found that at low speed, the film thickness of the grease was higher than that of the corresponding base oil film owing to the presence of the thickener fiber.

Laurentis et al. [16] experimentally measured the friction coefficients and film thickness of a series of commercial bearing greases and their bled oils. They also reported that for lithium greases, a thick film was formed at low speed, which was 3-10 times higher than that of their corresponding base oil film.

Recently, Kanazawa et al. [17] found that at low speed, the type of thickener played a decisive role in the film thickness of the grease regardless of the viscosity of the base oil and the test temperature. It was found that the fiber group played a vital role in the film formation when the entraining speed was below a critical speed, making the film thickness greater than the theoretical film thickness (when considering only base oil lubrication) [15-17]. Above that critical speed, the grease film thickness was identical to that of base oil lubrication. The change of grease film thickness against the entraining speed represented a V-shape.

Except the works of Li et al. [7, 8] and Wang et al. [9], all of the above experiments were carried out under a steady-state condition. The existence of thick grease film with the aid of thickener fiber at low speeds has become widely accepted. However, many machine elements work under long-period transient conditions. How the grease lubrication performs under transient conditions at a low entraining speed is unknown. Therefore, in this study, the grease distributions in a steady-state pure rolling condition and reciprocating rolling condition at low speeds over long working periods are compared to reveal the transient effect. For the reciprocating motion, the effects of the applied load, stroke length, and entraining speed were investigated.

\section{Experimental methods}

Experiments were conducted using a ball-on-disk apparatus. The contacting pairs were composed of a 25.4-mm-diameter steel ball and a glass disk with a diameter of $150 \mathrm{~mm}$ and thickness of $15 \mathrm{~mm}$. One side of the glass disk contacting with the steel ball was coated with a Cr layer that was approximately $20 \mathrm{~nm}$ thick in order to facilitate partial reflection. The properties of the steel ball and glass disk are listed in Table 1.

The commercially available greases Kluber Centoplex 3 and Centoplex 2EP were chosen. Either is a lithiumbased grease consisting of antioxidant mineral oil. Grease Centoplex 2EP has a lower cone penetration value. The properties are listed in Table 2.

All tests were conducted in a controlled laboratory environment at a constant room temperature of $23^{\circ} \mathrm{C}$.

The glass disk and the steel ball had a driving system that was composed of an AC servomotor, a

Table 1 Properties of ball and disk.

\begin{tabular}{lcc}
\hline \multicolumn{1}{c}{ Property } & Steel & Glass \\
\hline Young's modulus $(\mathrm{GPa})$ & 210 & 81 \\
Poisson's ratio & 0.3 & 0.208 \\
Density $\left(\mathrm{kg} / \mathrm{m}^{3}\right)$ & 7850 & 2510 \\
Thermal conductivity $(\mathrm{W} /(\mathrm{m} \cdot \mathrm{K}))$ & 46 & 1.11 \\
Specific heat $(\mathrm{J} /(\mathrm{kg} \cdot \mathrm{K}))$ & 470 & 840 \\
\hline
\end{tabular}


Table 2 Grease properties.

\begin{tabular}{ccc}
\hline Type & Centoplex 3 & Centoplex 2EP \\
\hline Base oil & Mineral oil & Mineral oil \\
Thickener & Lithium soap & Lithium soap \\
Temperature range $\left({ }^{\circ} \mathrm{C}\right)$ & -15 to 150 & -20 to 130 \\
Cone penetration & $220-250$ & $265-295$ \\
$\left(25^{\circ} \mathrm{C}, 0.1 \mathrm{~mm}\right)$ & & 180 \\
Base oil viscosity & 100 & 14 \\
$\left(40{ }^{\circ} \mathrm{C}, \mathrm{mm}^{2} / \mathrm{s}\right)$ & & \\
Base oil viscosity & 10 & \\
$\left(100{ }^{\circ} \mathrm{C}, \mathrm{mm}^{2} / \mathrm{s}\right)$ & & 2 \\
Dropping point & $>190$ & \\
DIN ISO $2176\left({ }^{\circ} \mathrm{C}\right)$ & 3 & \\
NLGI grade & &
\end{tabular}

high-precision reducer, and the coupling parts. A DFK 23G618 color camera was used as a charge coupled device (CCD) to capture images at a frequency of 120 frames per second. Red and green light sources were used in the experiments to illuminate the contact. The optical interference images were collected and then processed by software based on the dichromatic interference intensity modulation (DIIM) [18] technique in order to obtain the film thickness.

The ball and the disk moved in the form of a triangular wave. The trace plot and points of measurement are shown in Fig. 1 . With $T$ as the working period and $v_{\max }$ as the maximum surface speed, the stroke length $L$ is

$$
L=0.25 v_{\max } T
$$

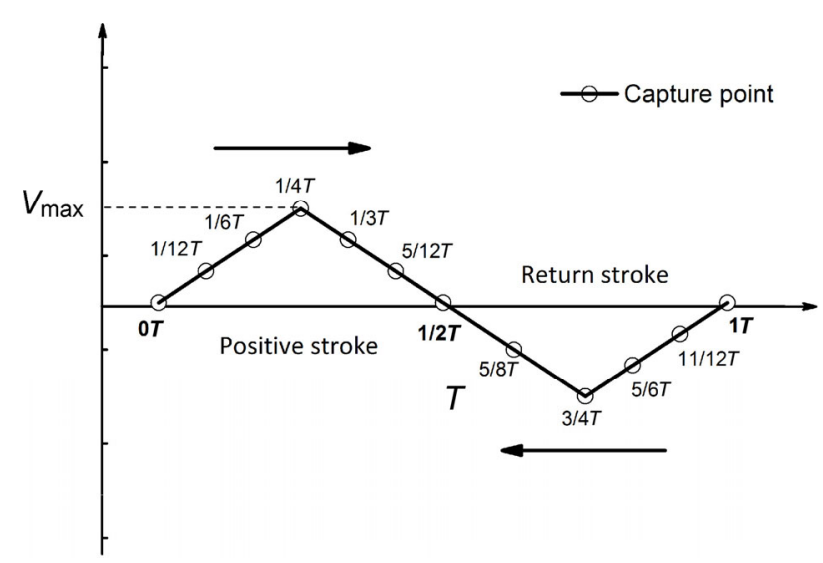

Fig. 1 Schematic diagram of reciprocating motion and trace points.

\section{Results and discussion}

In the following, experiments were first carried out under steady-state conditions and then under a reciprocating pure rolling motion. If not otherwise indicated, the results are presented mainly for the grease Centoplex 3.

\subsection{Steady state}

The variation of the central film thickness vs. the entrainment speed $v_{\mathrm{e}}\left(v_{\mathrm{e}}=v_{\mathrm{b}}+v_{\mathrm{d}}\right.$, where $v_{\mathrm{b}}$ and $v_{\mathrm{d}}$ are the surface speeds of the ball and the glass disk in the entraining direction, respectively) under the steady state is given in Fig. 2 with a load $w=50$ N. At higher speeds, the grease film thicknesses are practically identical to the solid line, which should be the film thickness obtained from the base oil $[16,17]$.

For the two greases used in the current work, the types of base oils were unknown. Thus, the solid lines were drawn according to the variation of the film thickness. However, this did not hinder us from determining the relation of the grease film thickness and a higher entraining speed. For Centoplex 3, below a speed of approximately $0.02 \mathrm{~m} / \mathrm{s}$, the grease film thickness started to increase, although with small undulations, as the entraining speed decreased.

Thus, a V-shape in the grease film thickness was formed, agreeing well with the findings in $[15,16]$. They $[15,16]$ referred to the speed at the inversion point of the "V" as the "transition speed." Above

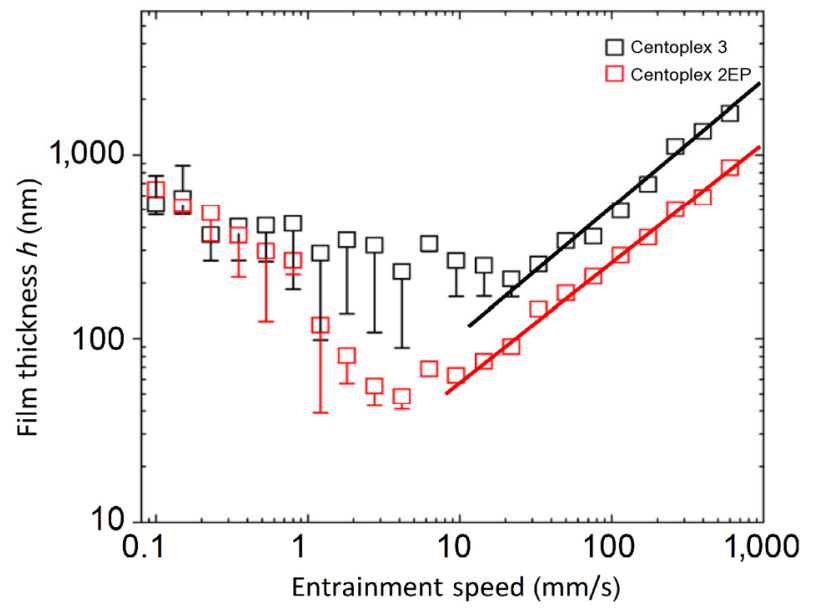

Fig. 2 Central film thickness vs. entrainment speed. 
the "transition speed," the thickener fiber usually does not enter the contact, and thus the film thickness is identical to that of the base oil. For the Centoplex 2EP grease, the lowest point of the V-shape was only $0.004 \mathrm{~m} / \mathrm{s}$.

Then, experiments with $v_{\mathrm{e}}=0.01 \mathrm{~m} / \mathrm{s}$ and $w=15 \mathrm{~N}$ were conducted. The glass disk was rotated for 500 cycles, which took nearly $6 \mathrm{~h}$ (1 cycle $T_{\mathrm{R}}$ (time of cycle) took about $42 \mathrm{~s}$ ). As shown in Fig. 3, the optical interferometric images of the grease film and the corresponding midsection film thicknesses at 4 time instants, i.e., $10.5 \mathrm{~s}, 21 \mathrm{~s}, 31.5 \mathrm{~s}$, and $42 \mathrm{~s}$, in the 1st and 500th cycles were selected. In each optical interferometric image, the EHL contact was filled with the thickener fiber. This phenomenon did not change from the 1st to the 500th rotation.

Owing to the existence of the thickener fiber, the midsection film thickness fluctuated irregularly in all of the images, with the average film thickness in the contact at around $0.2 \mu \mathrm{m}$. It was seen that for the 1st and 500th cycles, although they occurred during the same time instant, the distributions and fluctuations of the grease film were different, and the thickener fiber conglomerating in the conjunction was almost at the same amount.

Figure 4 shows the optical images and the corresponding midsection film thicknesses with $v_{\mathrm{e}}=$ $0.01 \mathrm{~m} / \mathrm{s}$ and $w=50 \mathrm{~N}$ for the four time instants, i.e., $10.5 \mathrm{~s}, 21 \mathrm{~s}, 31.5 \mathrm{~s}$, and $42 \mathrm{~s}$, in the 1st and 500th cycles. With a higher load, the contact area was enlarged, and thus a large amount of grease thickener fiber was observed in the contact, such as in Fig. 4(c) and Fig. 4(d). Thus, a larger amount of grease film fluctuated, with the maximum film thickness at around $0.3 \mu \mathrm{m}$ in Fig. 4(c) and a minimum film thickness of $0.06 \mu \mathrm{m}$ in Fig. 4(h). It was seen that in the 500th cycle, the thickener fiber was spread more uniformly slightly by the motion.

It was also seen that for the 1st and 500th cycles, the same as in Fig. 3, although at the same time instant, the distributions and fluctuations of grease film with the thickener fiber were different, the thickener fiber conglomerating in the conjunction was still at the same amount.

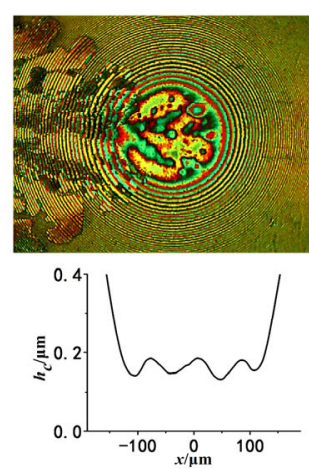

(a) $1 / 4 T_{\mathrm{R}}$

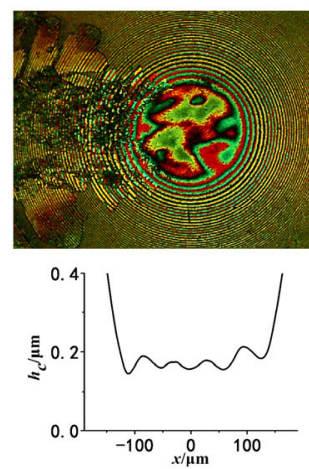

(e) $1 / 4 T_{\mathrm{R}}$

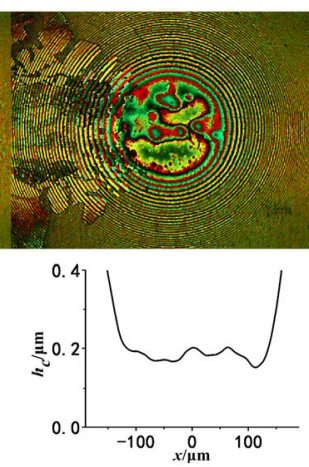

(b) $1 / 2 T_{\mathrm{R}}$

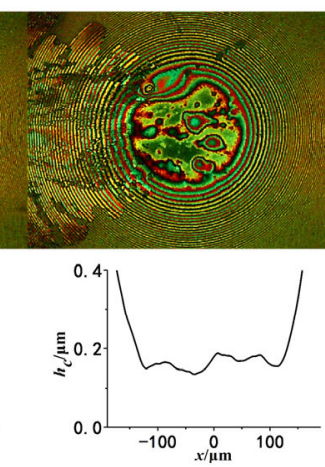

(c) $3 / 4 T_{\mathrm{R}}$

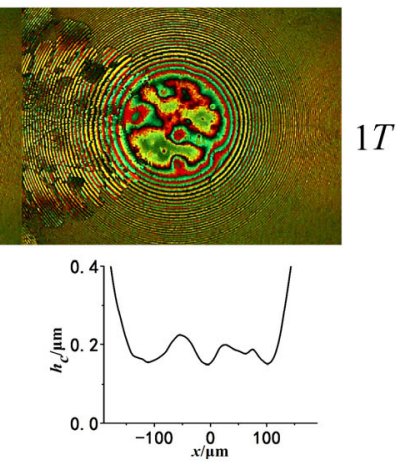

(d) $1 T_{\mathrm{R}}$

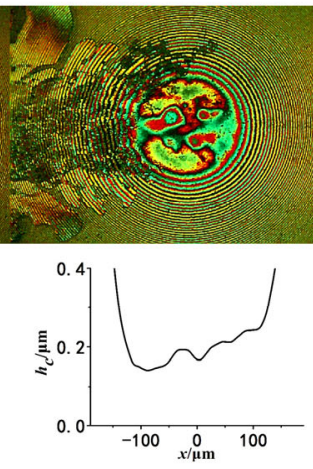

(f) $1 / 2 T_{R}$

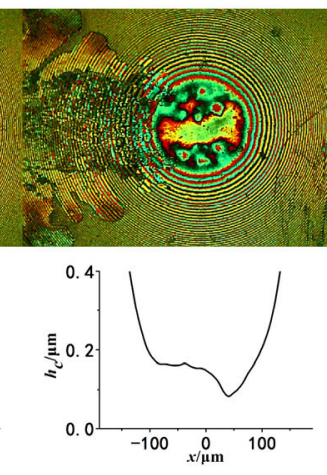

(g) $3 / 4 T_{R}$

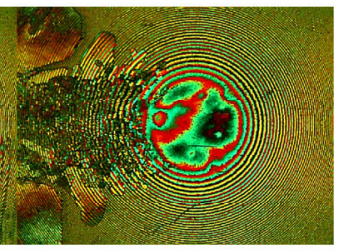

$500 T$

Fig. 3 Interferograms and midsection film thickness during $1 \mathrm{st}$ and 500 th cycle under pure rolling steady-state motion $\left(v_{\mathrm{e}}=0.01 \mathrm{~m} / \mathrm{s}\right.$, $w=15 \mathrm{~N})$. 
Figures 3 and 4 confirm that under steady-state conditions and specific working conditions, the existence of the thickener fiber was stable.

\subsection{Reciprocating motion}

Figure 5 shows the optical interferograms and the midsection thickness profiles over the 1st cycle at the 12 trace points shown in Fig. 1 for $v_{\max }=0.01 \mathrm{~m} / \mathrm{s}, w=$ $15 \mathrm{~N}$, and $T=0.5 \mathrm{~s}$ with a reciprocating stroke $L$ of $1.25 \mathrm{~mm}$. The maximum speed $v_{\max }$ and the applied load $w$ are the same as the entraining speed and the load, respectively, in Fig. 3. In Figs. 5(b)-5(f), the motion is from the right to the left, while in Figs. $5(\mathrm{~h})-5(\mathrm{k})$, the motion is in the opposite direction.

Figures 5(a), 5(g), and 5(1) are at the stroke end with zero surface speeds. Figures 5(d) and 5(j) are at the stroke center, where the entraining speed reached a maximum of $0.01 \mathrm{~m} / \mathrm{s}$. In Fig. 5, over the entire workingcycle, the grease film distribution did not exhibit the typical feature of reciprocating oil film: the entrapment of lubricant at the stroke end when the maximum central film arrived at its maximum just a little after the stroke center $[4,5]$.

In all of the optical interferometric images, there exists thickener fiber in the contacts. The midsection film thickness was influenced significantly by the thickener fiber. Where there was an aggregation of thickener fiber, there was a local upward dimple in film thickness. On the other hand, the grease film thickness became thin where the thickener fiber was less or absent, such as in Fig. 5(d) and Fig. 5(i) at the stroke centers. The corresponding midsection film thickness fluctuated slightly where there was a small aggregation of thickener fiber.

At the stroke ends of Figs. 5(a) and 5(1), the grease film shapes as well as the midsection film thickness were not identical. The upward entrapment was mainly owing to the large or small aggregation of the thickener fiber, other than the squeeze effect $[4,5,8]$. If we compare Fig. 5 with Fig. 3, we can see that much of the thickener fiber was removed from the EHL contacts.

In Figs. 5(d) and 5(i), the entraining speed is the same as that in Fig. 3, but only a small amount of thickener fiber remained in the contact, and the

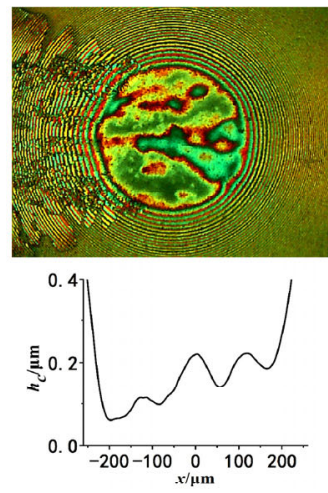

(a) $1 / 4 T_{\mathrm{R}}$

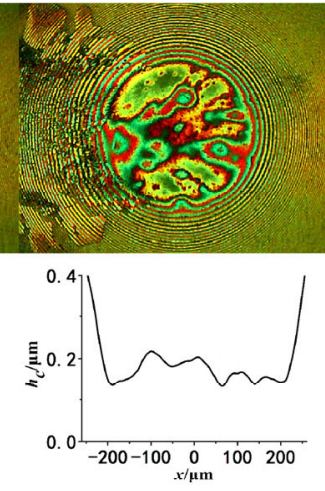

(b) $1 / 2 T_{\mathrm{R}}$

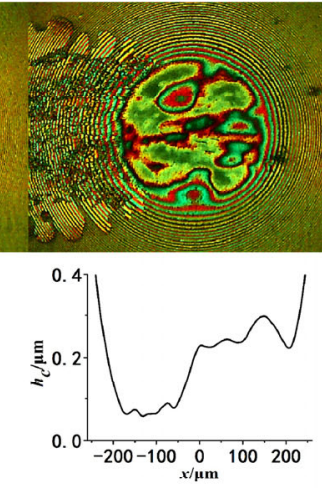

(c) $3 / 4 T_{R}$

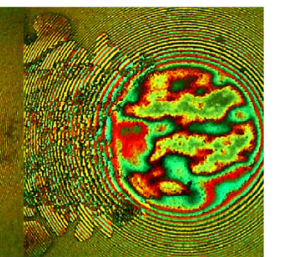

$1 T$

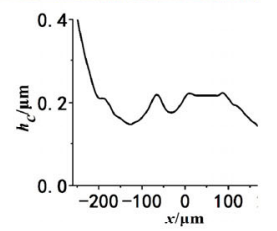

(d) $1 T_{\mathrm{R}}$

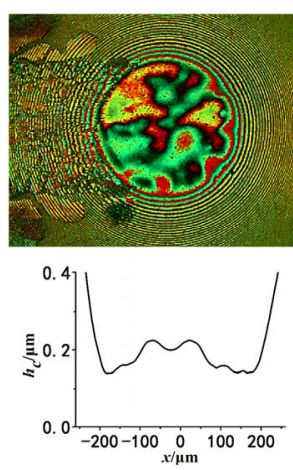

(e) $1 / 4 T_{R}$

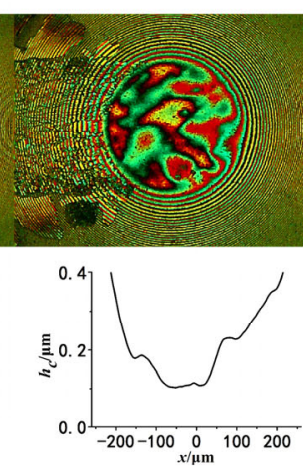

(f) $1 / 2 T_{R}$

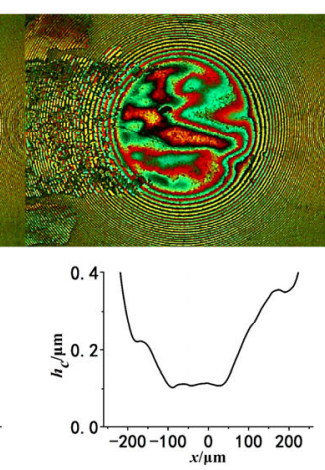

(g) $3 / 4 T_{R}$

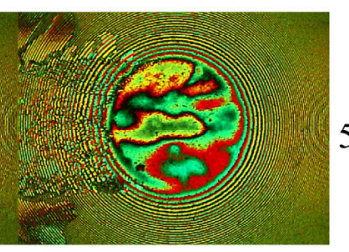

$500 T$

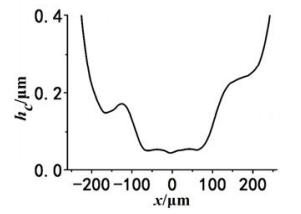

(h) $1 T_{\mathrm{R}}$

Fig. 4 Interferograms and midsection film thickness during $1 \mathrm{st}$ and 500 th cycle under pure rolling steady-state motion $\left(v_{\mathrm{e}}=0.01 \mathrm{~m} / \mathrm{s}\right.$, $w=50 \mathrm{~N})$. 


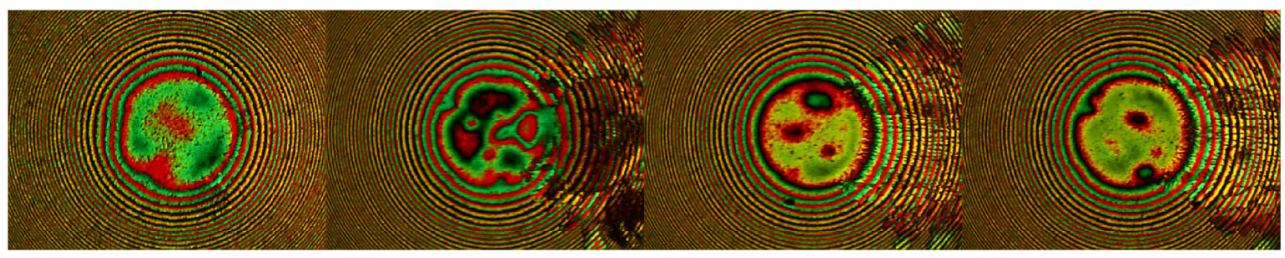

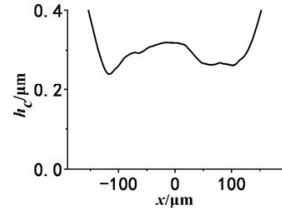

(a) $0 T$

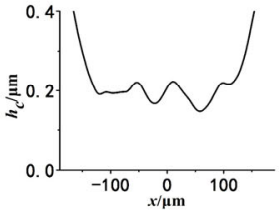

(b) $1 / 12 T$

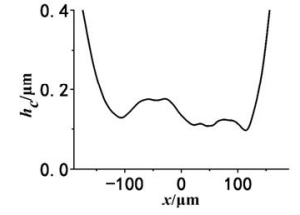

(c) $1 / 6 \mathrm{~T}$

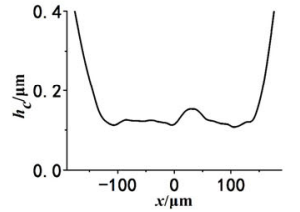

(d) $1 / 4 T$

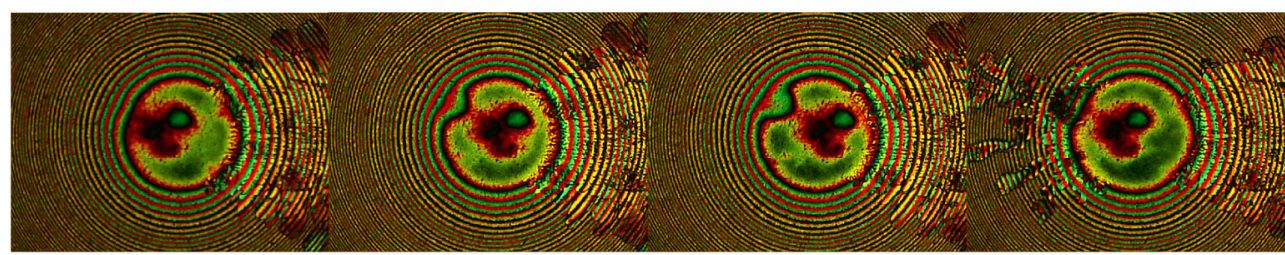

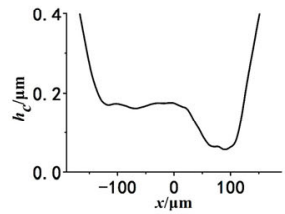

(e) $1 / 3 T$

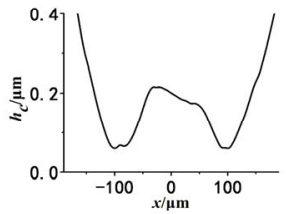

(f) $5 / 12 T$

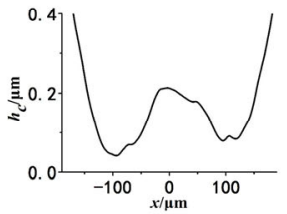

(g) $1 / 2 T$

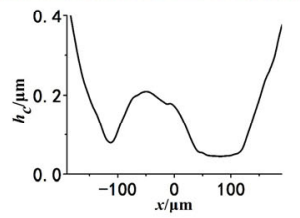

(h) $5 / 8 \mathrm{~T}$

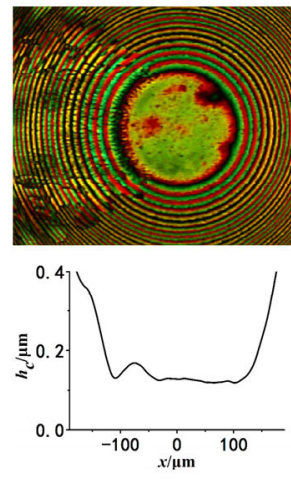

(i) $3 / 4 T$

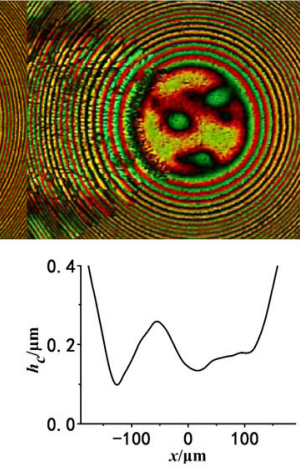

(j) $5 / 6 \mathrm{~T}$

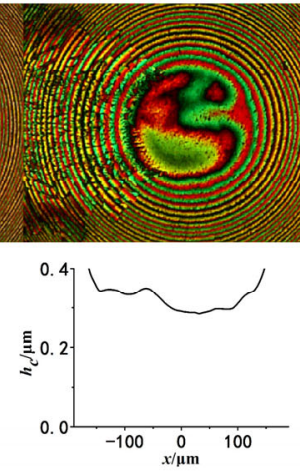

(k) $11 / 12 T$
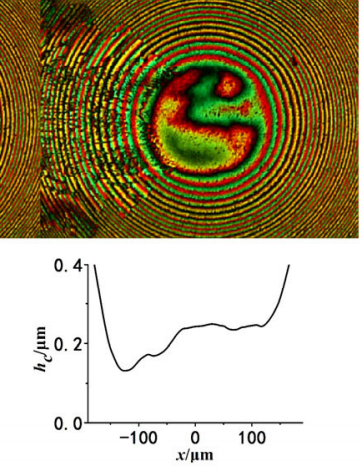

(1) $1 T$

Fig. 5 Interferograms and midsection film thickness during 1 st cycle under pure rolling reciprocating motion $\left(v_{\max }=0.01 \mathrm{~m} / \mathrm{s}, w=15 \mathrm{~N}\right.$, $T=0.5 \mathrm{~s}, L=1.25 \mathrm{~mm})$.

midsection film thickness in Figs. 5(d) and 5(i) was around $40 \%$ smaller than that in Fig. 3. Moreover, the obvious upward entrapment shown in Figs. 5(e)-5(h) is a stochastic phenomenon as the large or small aggregation of the thickener fiber was not fixed.

In Fig. 5(h), the previous cavitation zone turned into an inlet starvation zone, resulting in a reduction in film thickness at the right side. Therefore, the variation and thickness of the grease film was dominated by the thickener fiber, although the entraining speed also exerted a small influence.
Figure 6 shows the results for the 5 th cycle. The film shape shown in Figs. 6(c), 6(d), 6(i), and 6(j) takes on the EHL film shape at a low entraining speed. Compared with Fig. 5, there are differences as described below. First, the midsection film thickness was obviously reduced, especially in Figs. 6(a)-6(c) and $6(j)-6(1)$. Second, the thickener fiber in the contacts of Fig. 6 was much less than that in Fig. 5.

Third, in Figs. 6(a) and 6(l), a chunk of thickener fiber appeared, demonstrating that there was a replenishment of grease from the sides of the running 


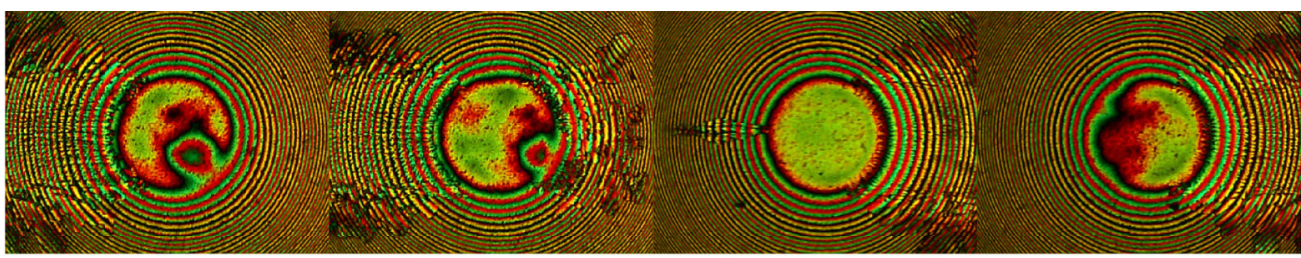

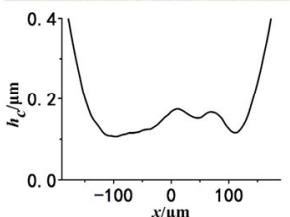

(a) $0 T$

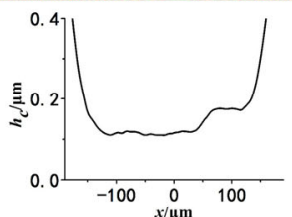

(b) $1 / 12 T$

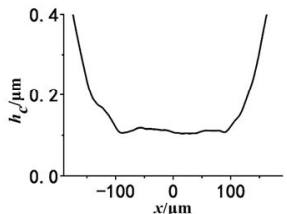

(c) $1 / 6 T$

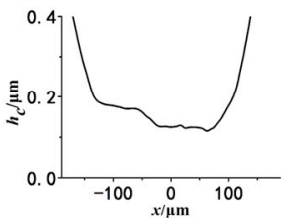

(d) $1 / 4 T$

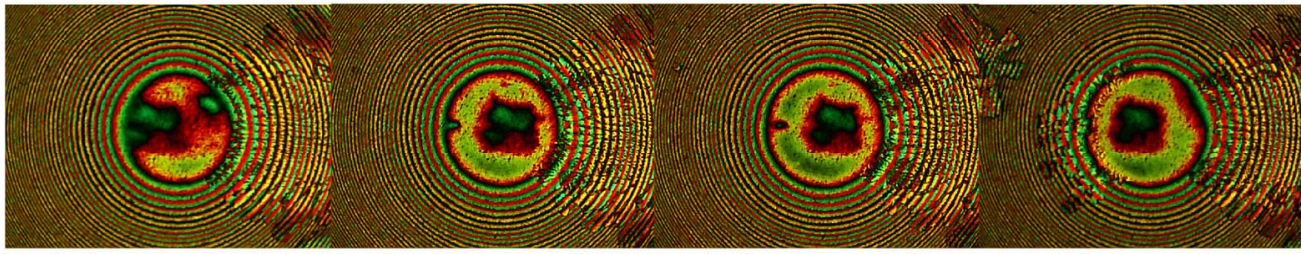

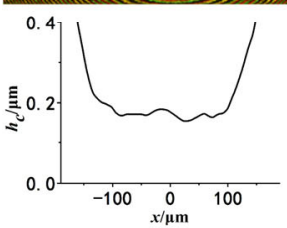

(e) $1 / 3 T$

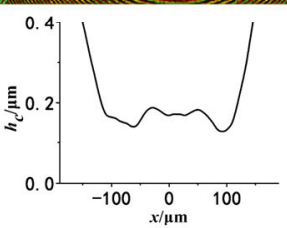

(f) $5 / 12 T$

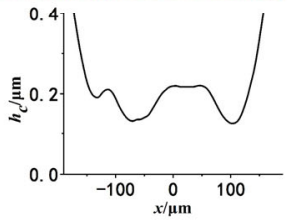

(g) $1 / 2 T$

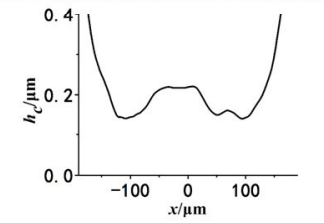

(h) $5 / 8 T$

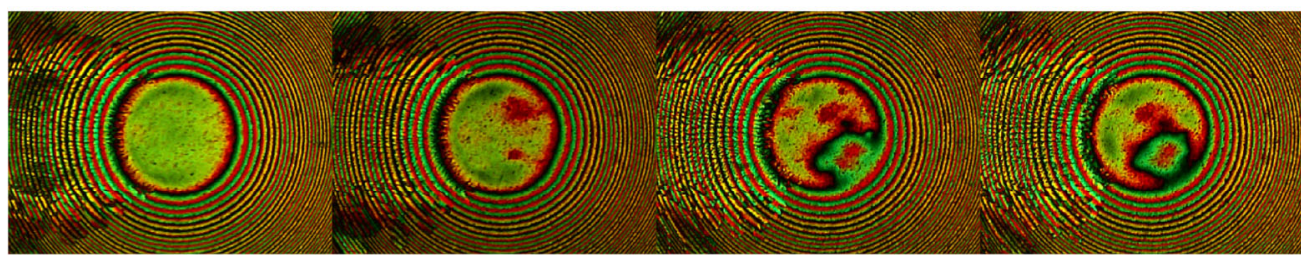

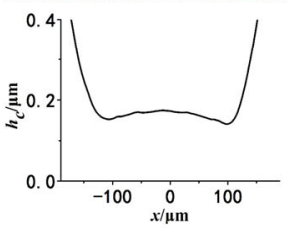

(i) $3 / 4 T$

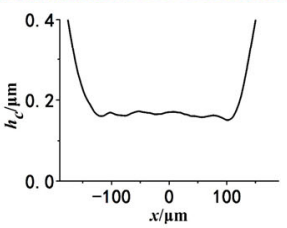

(j) $5 / 6 T$

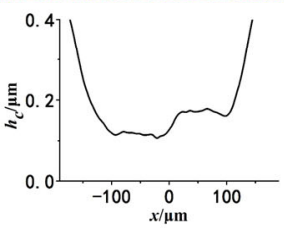

(k) $11 / 12 T$

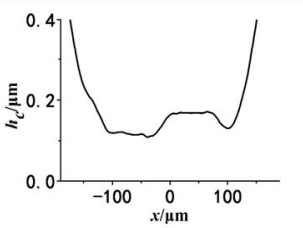

(l) $1 T$

Fig. 6 Interferograms and midsection film thickness during 5 th cycle under pure rolling reciprocating $\operatorname{motion}\left(v_{\max }=0.01 \mathrm{~m} / \mathrm{s}, w=15 \mathrm{~N}\right.$, $T=0.5 \mathrm{~s}, L=1.25 \mathrm{~mm})$.

track. What is worth explaining here is that the grease thickener fiber was not fixed at the same location and should have been in a dynamic state. Comparing the interferograms at the stroke ends of the first cycle and the 5th cycle (Fig. 5(1) and Fig. 6(1)), the morphology and location of the grease fiber are different. In addition, during the entire experimental process, the grease thickener fiber at the stroke end sometimes disappeared or became less and then appears again. Thus, the authors assume the reappearance was caused by grease replenishment.

Figure 7 gives the results for the 1,000th cycle. Very severe grease starvation occurred, and there was very little thickener fiber left in the contact zone. The remaining thickener fiber fluctuated with the film's thickness very locally, such as in Figs. 7(a), 7(b), 7(e), and 7(h) or in Figs. 7(j)-7(l). The dark rectangle shown, for example, in Figs. 7(a), 7(i), 7(k), and 7(l) or the triangular shape in Figs. 7(e)-7(g), represent the shape of the inlet grease starvation zone, which is actually 


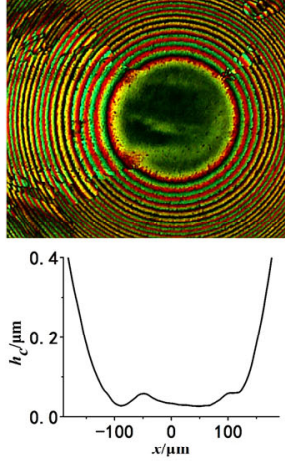

(a) $0 T$

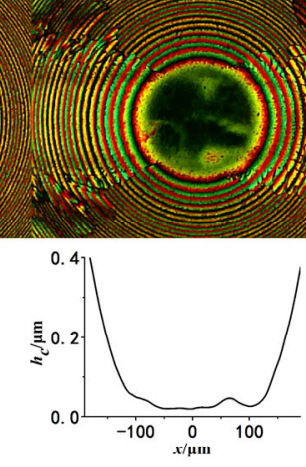

(b) $1 / 12 T$
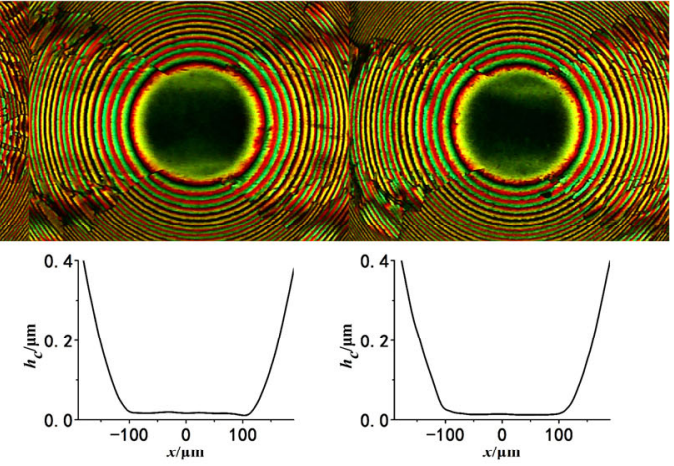

(c) $1 / 6 T$

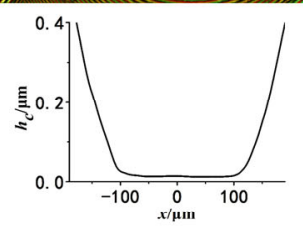

(d) $1 / 4 T$

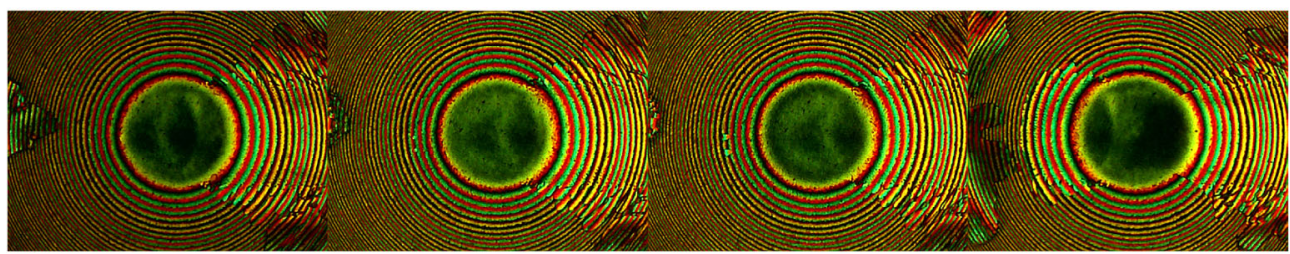

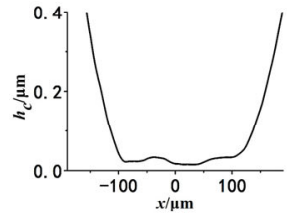

(e) $1 / 3 T$

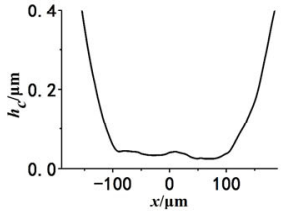

(f) $5 / 12 T$

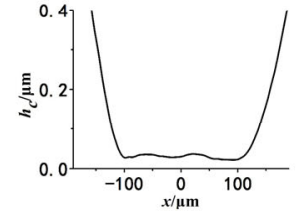

(g) $1 / 2 T$

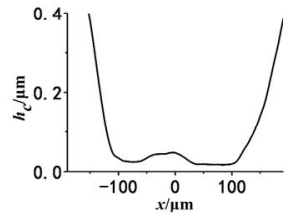

(h) $5 / 8 \mathrm{~T}$

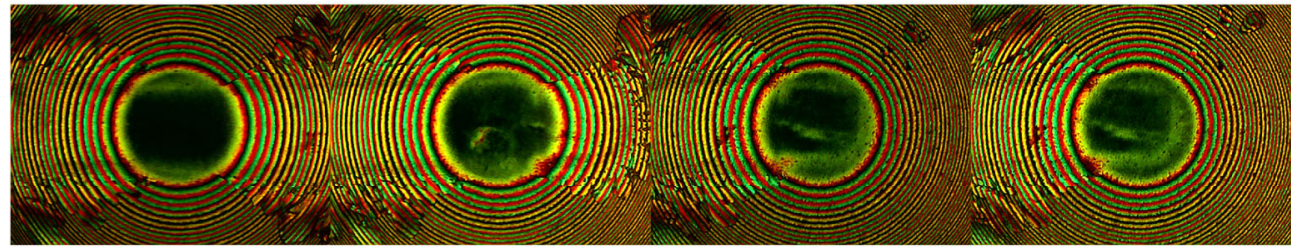

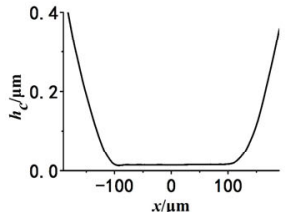

(i) $3 / 4 T$

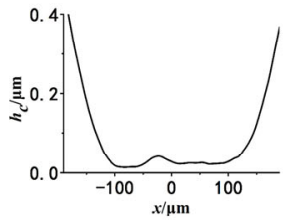

(j) $5 / 6 \mathrm{~T}$

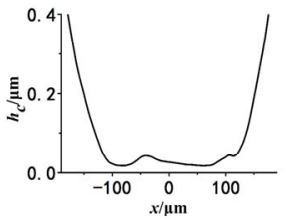

(k) $11 / 12 T$

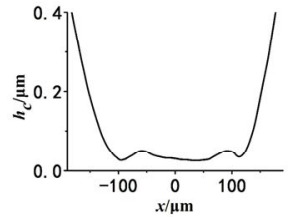

(1) $1 T$

Fig. 7 Interferograms and midsection film thickness during 1,000 th cycle under pure rolling reciprocating motion $\left(v_{\max }=0.01 \mathrm{~m} / \mathrm{s}\right.$, $w=15 \mathrm{~N}, T=0.5 \mathrm{~s}, L=1.25 \mathrm{~mm})$.

the shape of the outlet cavitation zone in the previous stroke.

Figure 8 illustrates the variation of the central film thickness of 18 selected working cycles. With a small number of working cycles from $1-5$, it is seen that the maximum central film thickness existed around the stroke end, other than around the stroke center. Like the contact in the steady state, the thickener fiber was conglomerated in the contact with a low or zero entraining speed. By contrast, around the contact center, where the entraining speed was below the "critical speed" of $0.02 \mathrm{~m} / \mathrm{s}$, much of the thickener fiber was removed from the contact so that the film thickness became low.

It is also seen that the five curves do not coincide with each other. At around 0.4T-0.6T, the thickness of the 1st cycle was nearly the smallest, thus demonstrating that the distribution of the grease thickener fiber was not fixed at the same location. Rather, it should have been in a dynamic state, affected by the motion and 


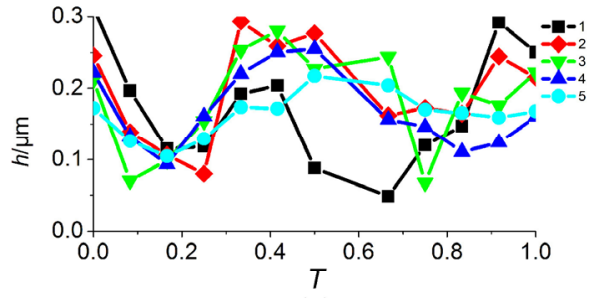

(a)

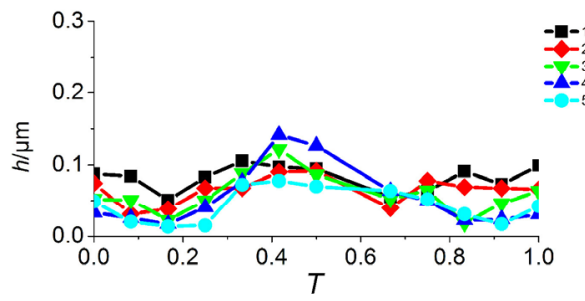

(c)

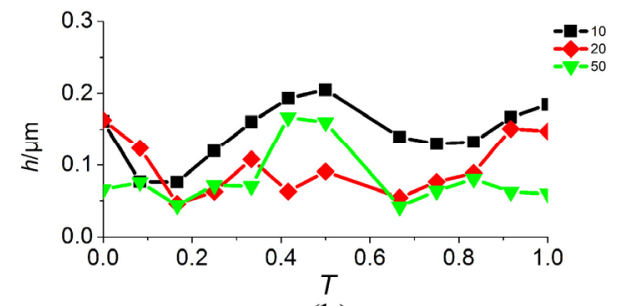

(b)

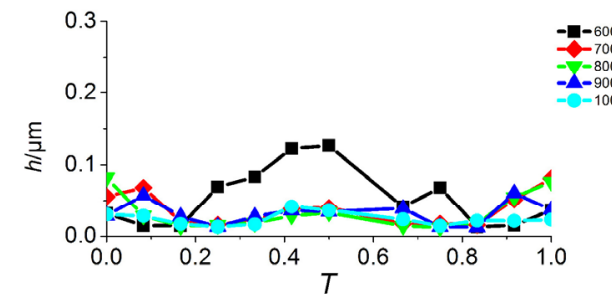

(d)

Fig. 8 Variation of central film thickness in some typical working periods ( $\left.v_{\max }=0.01 \mathrm{~m} / \mathrm{s}, w=15 \mathrm{~N}, T=0.5 \mathrm{~s}, L=1.25 \mathrm{~mm}\right)$

the replenishment. Figure $8(\mathrm{~b})$ shows the results for the 10th, 20th, and 50th cycles. The film thickness in the 10th cycle is the thickest, but those of the 20th and 50th cycles surpass each other at some points in the cycle. Generally speaking, the film thickness is reduced with an increase in the number of working cycles.

Figure 8(c) shows the results for the 100th, 200th, 300th, 400th, and 500th cycles. The five curves resemble each other and decrease with an increase in the cycle number, but not as drastically as shown in Fig. 8(b). Figure $8(\mathrm{~d})$ shows the results for the 600th, 700th, 800th, 900th, and 1,000th working cycles. That of the 600th cycle has a shape similar to those in Fig. 8(c).

The other four curves nearly overlap with each other and become constant over one working cycle. This indicates that under very severe starvation conditions, there was a very thin layer of lubricant remaining between the two surfaces so that the change in the entraining speed in the triangular form had no impact. This feature of the film thickness becoming constant after many cycles was shown by Wang et al. [9] in grease experiments with a reciprocating sliding motion.

Figure 9 shows the variations of the minimum film thickness over a number of selected working cycles with $v_{\max }=0.01 \mathrm{~m} / \mathrm{s}, w=15 \mathrm{~N}, T=0.5 \mathrm{~s}$, and $L=1.25 \mathrm{~mm}$. Figure 9(a) shows the minimum film thickness changes in cycles 1-5. It can be seen that the change in the film was more drastic owing to the existence of the fiber clusters. The film thicknesses in the 10th, 20th, and 50th cycles are shown in Fig. 9(b), in which the minimum film thicknesses of the 20th and the 50th cycles are lower than those of the 10th cycles owing to obvious grease starvation.

The three curves in Fig. 9(b) follow the variation of the entraining speed, i.e., they obtained their minimum values at the stroke end while reaching their maximum values around the stroke center. This is because with such a low velocity and a light load, the minimum film thickness rested at the boundary of the Hertzian circle, where large thickener fiber clusters usually do not exist.

In Fig. 9(c), the curves for the 100th, 200th, 300th, 400th, and 500th cycles follow the same shape as that in Fig. 9(b), although with an increasing number of working cycles, the general value of the minimum film thickness decreases. For the curves of the 400th and 600th cycles, the value around $0.4-0.6$ suddenly increases. This should be generated by grease replenishment. From the 700th cycle, the minimum film thickness falls to a horizontal line.

In Fig. 4, the thickener fiber aggregates in the form of irregular strips. The average film thickness was around $0.2 \mu \mathrm{m}$ and did not change much over long working cycles. Figure 10 shows optical interferometric images and corresponding midsection film thicknesses with a heavier load $w=50 \mathrm{~N}$ and all other parameters remaining unchanged.

In Fig. 10, the thickener fiber aggregates in large or 


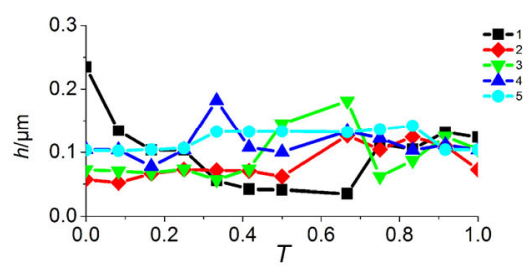

(a)

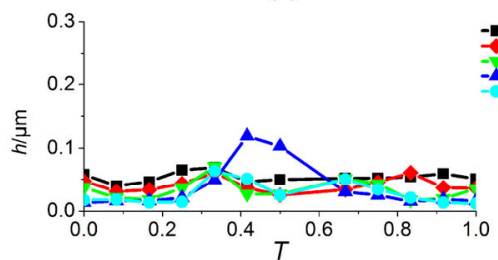

(c)

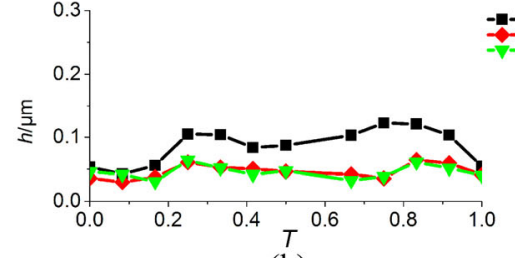

(b)

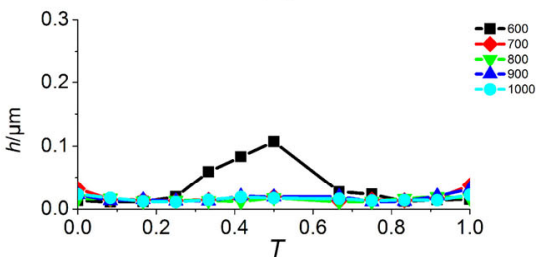

(d)

Fig. 9 Variation of minimum film thickness in some typical working periods ( $\left.v_{\max }=0.01 \mathrm{~m} / \mathrm{s}, w=15 \mathrm{~N}, T=0.5 \mathrm{~s}, L=1.25 \mathrm{~mm}\right)$.

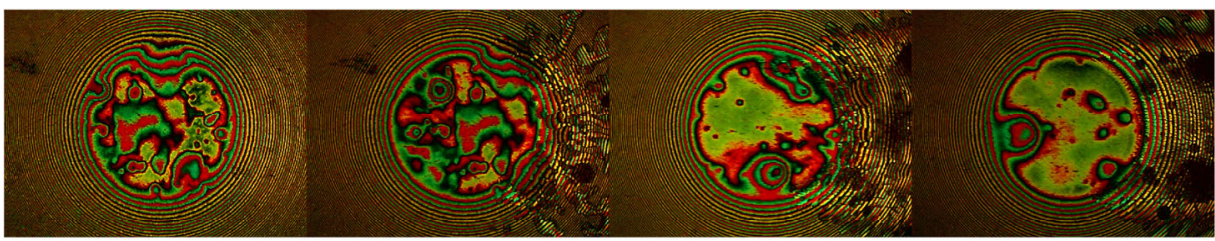

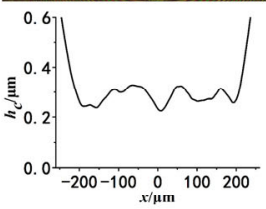

(a) $0 T$

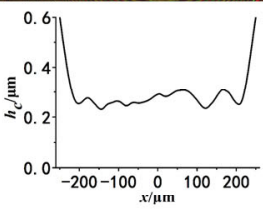

(b) $1 / 12 T$

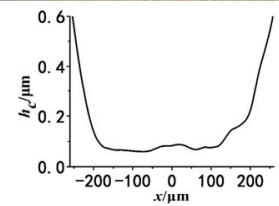

(c) $1 / 6 T$

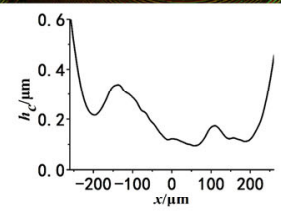

(d) $1 / 4 T$

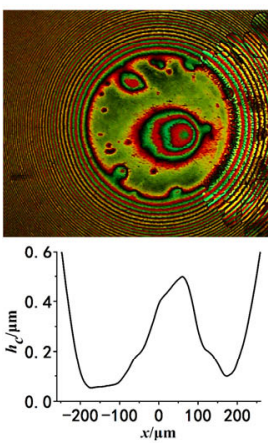

(c) $1 / 3 T$

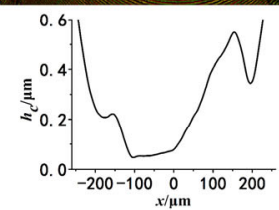

(f) $5 / 12 \mathrm{~T}$

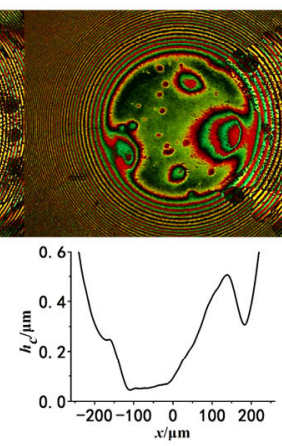

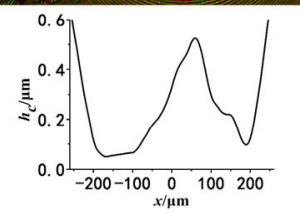

(h) $5 / 8 T$

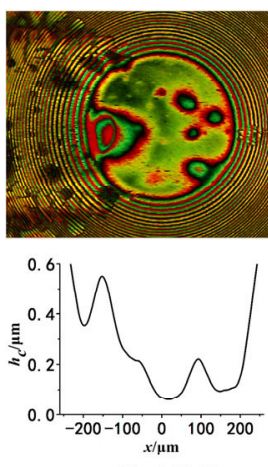

(i) $3 / 4 T$

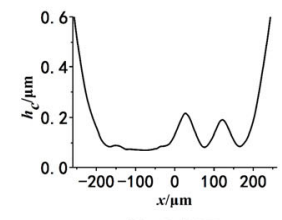

(j) $5 / 6 T$ (g) $1 / 2 T$

mone
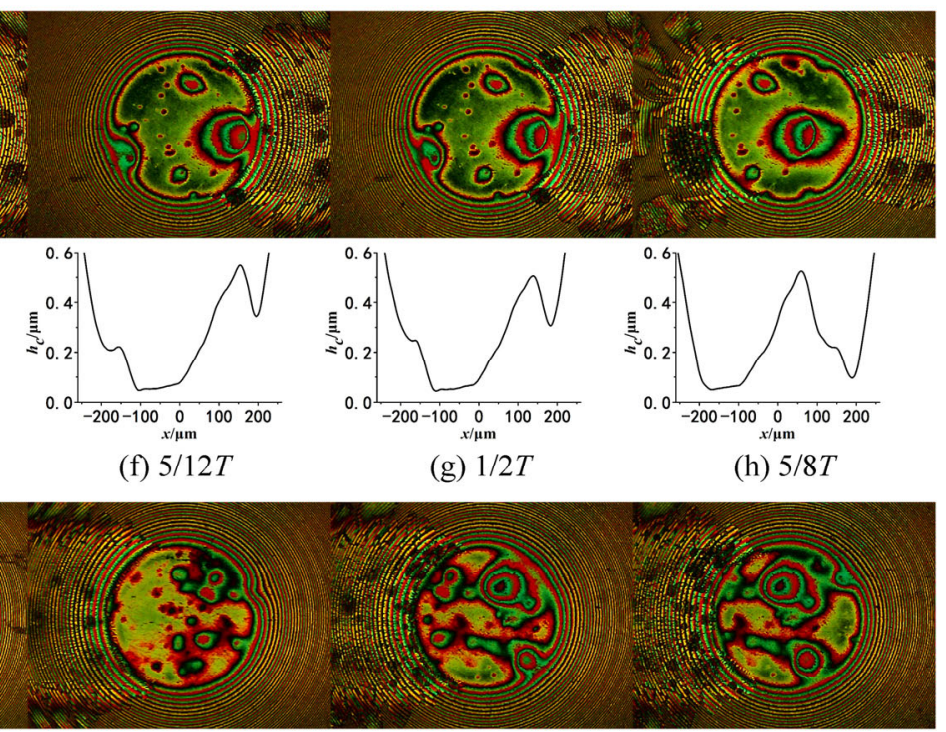

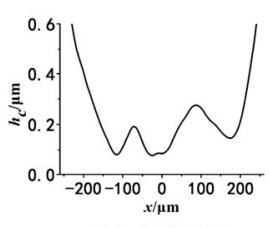

(k) $11 / 12 T$

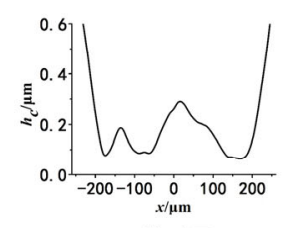

(1) $1 T$

Fig. 10 Interferograms and midsection film thickness during 1 st cycle under pure rolling reciprocating $\operatorname{motion}\left(v_{\max }=0.01 \mathrm{~m} / \mathrm{s}, w=50 \mathrm{~N}\right.$, $T=0.5 \mathrm{~s}, L=1.25 \mathrm{~mm})$. 
small circular heaps. In the beginning of the motion, in Figs. 10(a) and 10(b), the film thickness was quite thick at around $0.3 \mu \mathrm{m}$ (the entraining speeds were 0 and $0.0033 \mathrm{~m} / \mathrm{s}$, respectively). There is nearly as much thickener fiber in Figs. 10(a) and 10(b) as in Fig. 4. With an increase in the entraining velocity, much of the thickener fiber was removed from the contact.

However, there was still a large heap generating a large upward dimple and several small heaps of thickener fiber generating small fluctuations in the film thickness. Where there was no thickener fiber, the film thickness was small, for example, at $0.06 \mu \mathrm{m}$ in Fig. 10(f). The large accumulation of thickener fiber reached a diameter of about $150 \mu \mathrm{m}$ (as shown in Figs. $10(\mathrm{e})$ and $10(\mathrm{~h})$ ), which was $3 / 4$ of the radius of the Hertzian contact radius. At the stroke center (Figs. 10(d) and 10(i)), there was less accumulation of the thickener fiber. In comparing Figs. 5(d) and 5(i), the size of the accumulated thickener fiber is prominent.

Figure 11 presents the results for the 5th working cycle. In Figs. 11(a)-11(d), the size of the aggregation of the thickener fiber becomes much smaller and also irregular. In other figures, the thickener fiber appears as a circular aggregation. The large circular aggregation has a diameter of only $50 \mu \mathrm{m}$. In Figs. 11(a), 11(b), $11(\mathrm{k})$, and 11(1), the average film thickness was $0.2 \mu \mathrm{m}$,

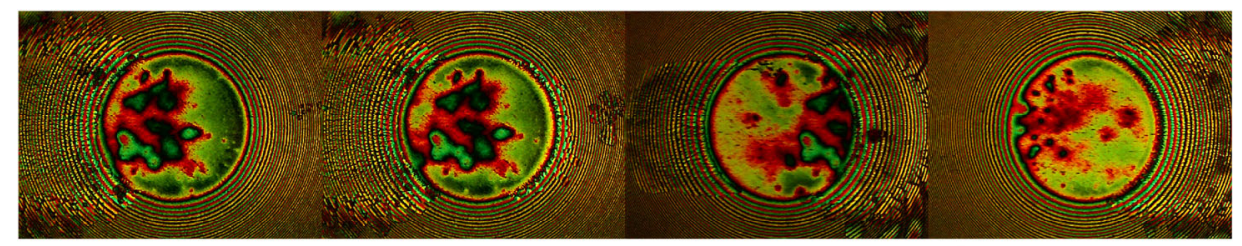

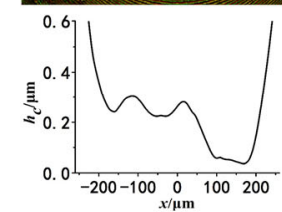

(a) $0 T$

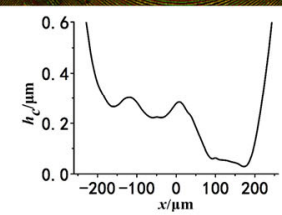

(b) $1 / 12 T$

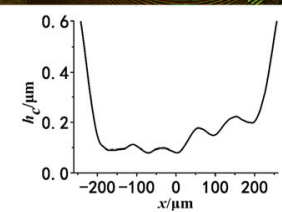

(c) $1 / 6 T$

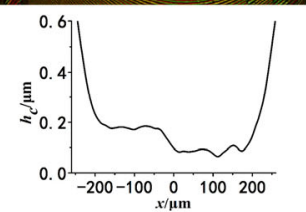

(d) $1 / 4 T$

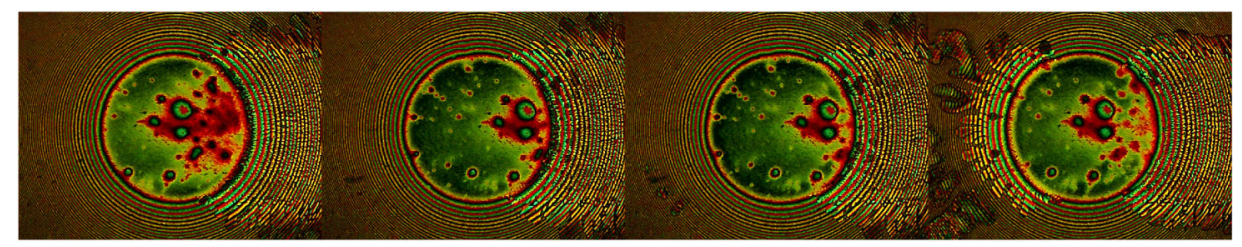

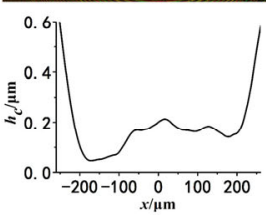

(c) $1 / 3 T$

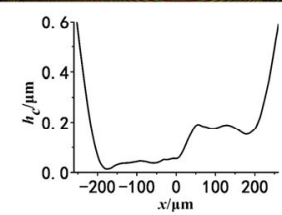

(f) $5 / 12 \mathrm{~T}$

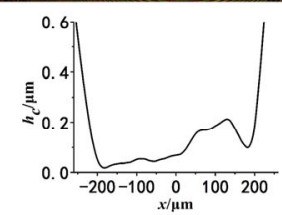

(g) $1 / 2 T$

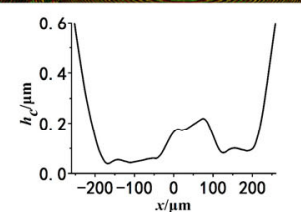

(h) $5 / 8 \mathrm{~T}$

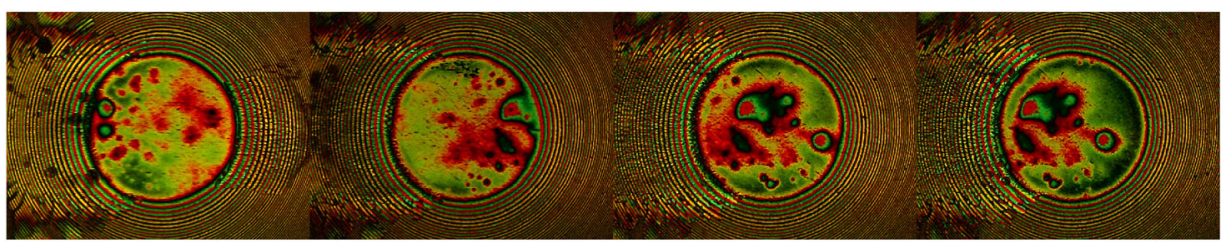

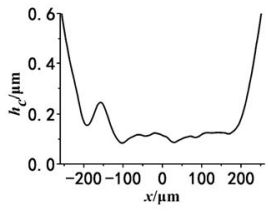

(i) $3 / 4 T$

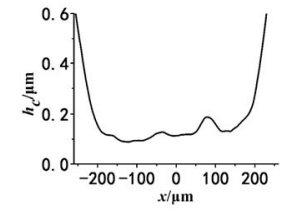

(j) $5 / 6 \mathrm{~T}$

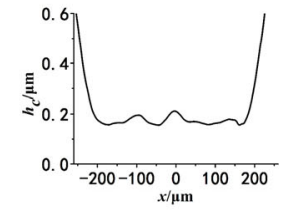

(k) $11 / 12 T$

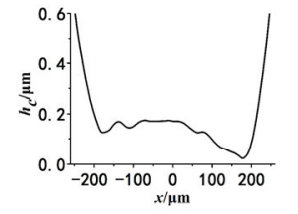

(1) $1 T$

Fig. 11 Interferograms and midsection film thickness during 5 th cycle under pure rolling reciprocating $\operatorname{motion}\left(v_{\max }=0.01 \mathrm{~m} / \mathrm{s}, w=50 \mathrm{~N}\right.$, $T=0.5 \mathrm{~s}, L=1.25 \mathrm{~mm})$. 
while in the other figures, the average film thickness is reduced to $0.1 \mu \mathrm{m}$ by the reduction in the thickener fiber aggregation size. An obvious reduction in film thickness is seen where there was no thickener fiber aggregation.

Figure 12 shows the results for the 100th cycle. From the startup of the motion, only $50 \mathrm{~s}$ passed. With a heavier load, the occurrence of grease starvation occurred much earlier. A severe grease starvation zone is observed in every figure. The zone has a long diamond shape (drawn with a blue solid line). This zone can enter the contact area and move back and forth by the motion. Depending on the motion of the inlet starvation zone, the zone usually appears as a dark triangle of different sizes.

In Fig. 12, the thickener fiber exists in a bean shape. The majority of the aggregations of the thickener fiber had a diameter 1-3 $\mu \mathrm{m}$. The largest one was around $20 \mu \mathrm{m}$ in diameter. The inlet starvation zone is much larger, but only this diamond zone produces a significant effect on the film thickness. It is seen that the overall film thickness was reduced, and the average film thickness was around $0.05 \mu \mathrm{m}$. These small aggregations caused only small fluctuations.

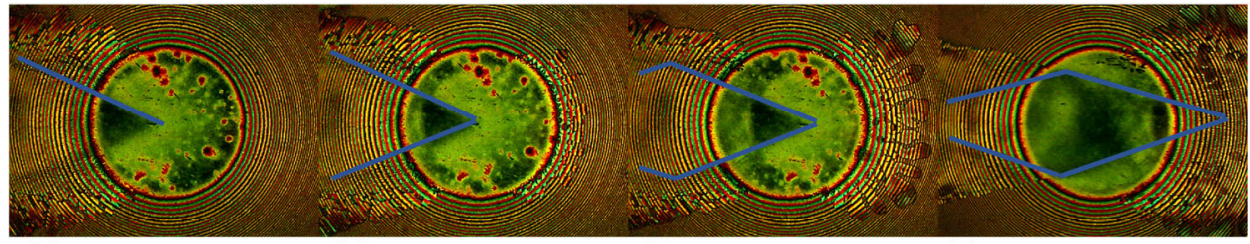

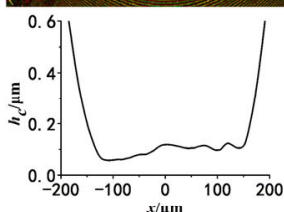

(a) $0 \mathrm{~T}$

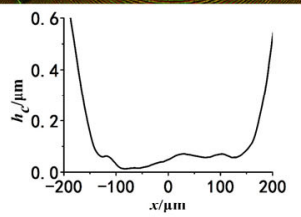

(b) $1 / 121$

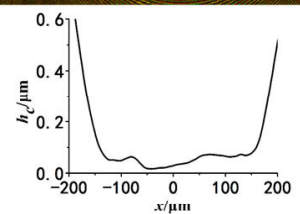

(c) $1 / 6 T$

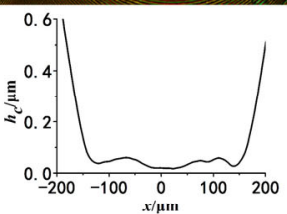

(d) $1 / 4 T$

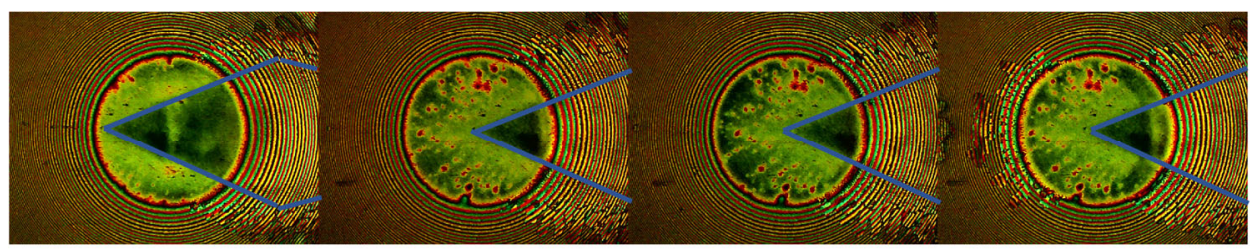

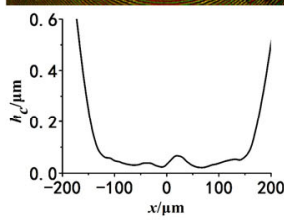

(e) $1 / 3 T$

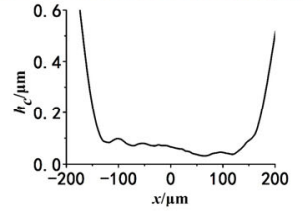

(f) $5 / 12 T$

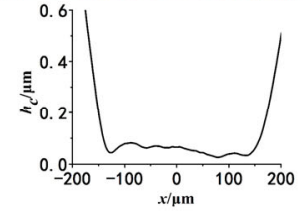

(g) $1 / 2 T$

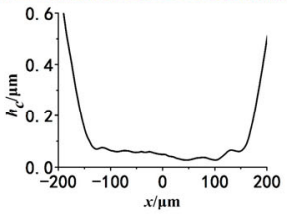

(h) $5 / 8 T$

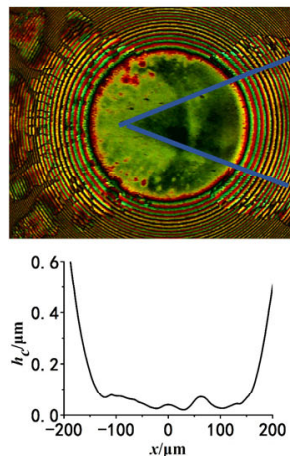

(i) $3 / 4 T$

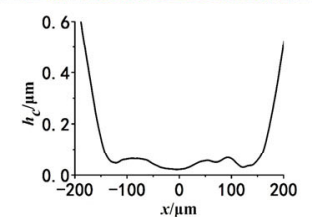

(j) $5 / 61$

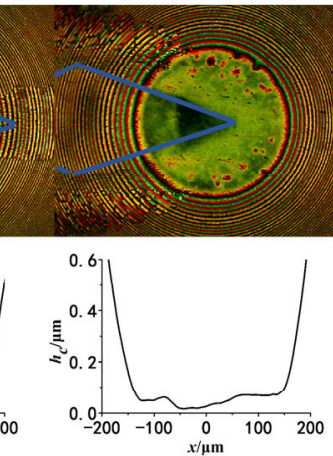

(k) $11 / 12 T$

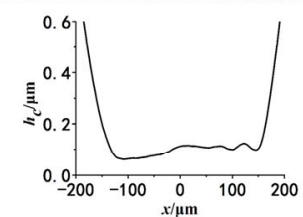

(l) $1 T$

Fig. 12 Interferograms and midsection film thickness during 100 th cycle under pure rolling reciprocating $\operatorname{motion}\left(v_{\max }=0.01 \mathrm{~m} / \mathrm{s}\right.$, $w=50 \mathrm{~N}, T=0.5 \mathrm{~s}, L=1.25 \mathrm{~mm})$. 
The diamond-shaped starvation zone grows with an increase in the starvation severity. At the 1,000th cycle as shown in Fig. 13, very severe starvation occurs, and the starved triangle disappears. The aggregations of the thickener fiber behave like a floccus dispersion. Then, the average film thickness was only around $10 \mathrm{~nm}$. It is difficult to distinguish the stroke center and the stroke end.

Figure 14 shows the variation of the central film thickness for $v_{\max }=0.01 \mathrm{~m} / \mathrm{s}, w=50 \mathrm{~N}, T=0.5 \mathrm{~s}$, and $L=1.25 \mathrm{~mm}$. The central film thickness fluctuated drastically across $1-5$ cycles. The same as what is shown in Fig. 8(a), at the stroke ends, the thickness is great, while at the stroke center it is thin. Generally, it tends to decrease. After 20 cycles, with local small fluctuations, the central film thickness decreased with an increase in the working cycle and is barely influenced by the entraining speed. In Fig. 8, with a small load of $15 \mathrm{~N}$, this severe starvation occurs after 700 cycles.

Figure 15 shows the changes in the minimum film thickness. Different from the variation in the central film thickness, the minimum film thickness in the

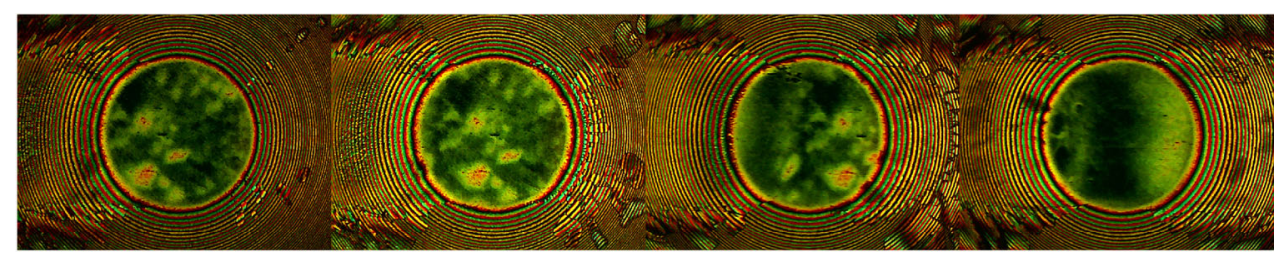

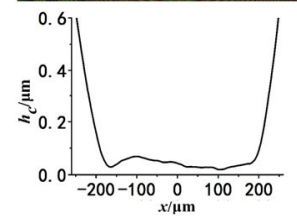

(a) $0 T$

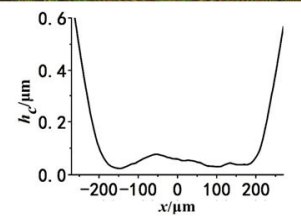

(b) $1 / 12 T$

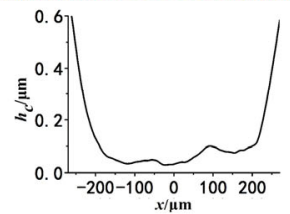

(c) $1 / 6 T$

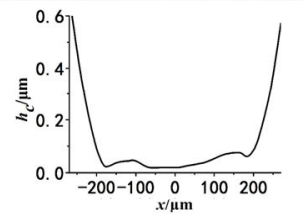

(d) $1 / 4 T$

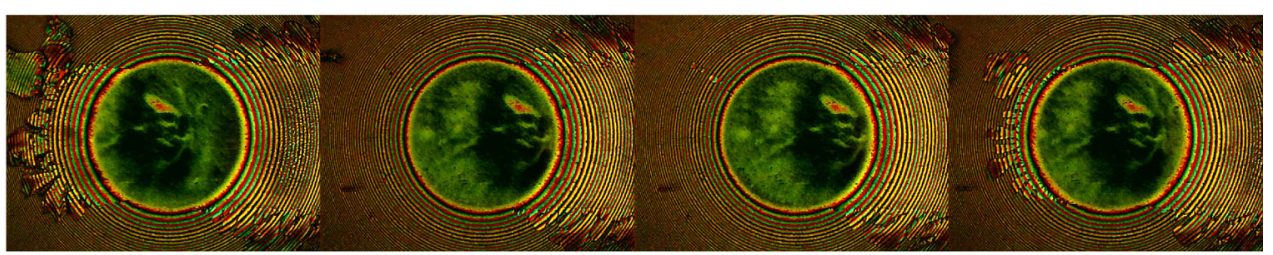

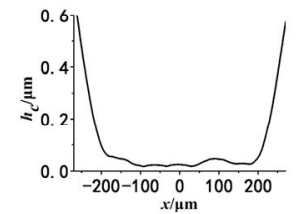

(e) $1 / 3 T$

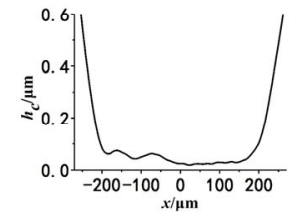

(f) $5 / 12 T$

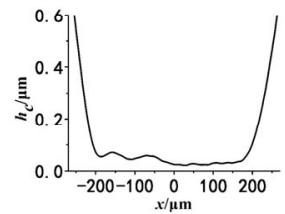

(g) $1 / 2 T$

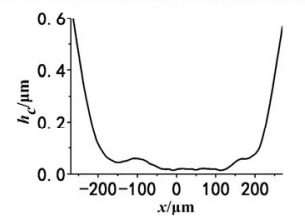

(h) $5 / 8 T$

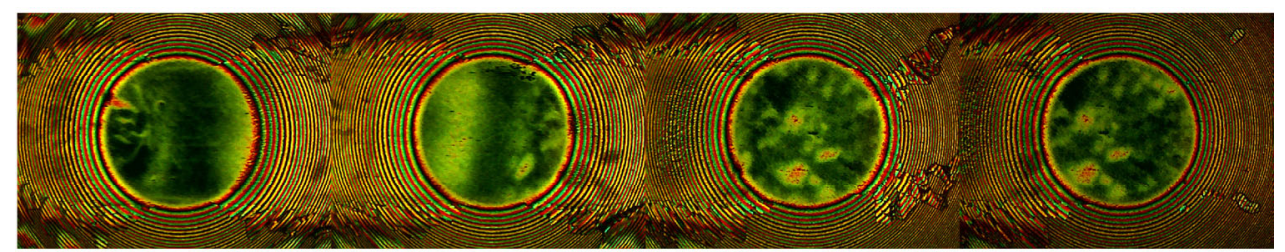

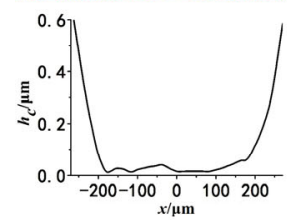

(i) $3 / 4 T$

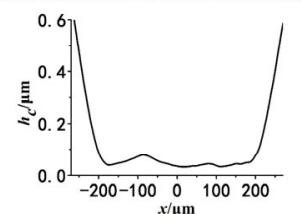

(j) $5 / 6 T$

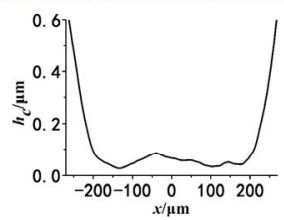

(k) $11 / 12 T$

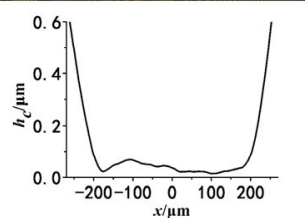

(1) $1 T$

Fig. 13 Interferograms and midsection film thickness during 1,000 th cycle under pure rolling reciprocating $\operatorname{motion}\left(v_{\max }=0.01 \mathrm{~m} / \mathrm{s}\right.$, $w=50 \mathrm{~N}, T=0.5 \mathrm{~s}, L=1.25 \mathrm{~mm})$. 


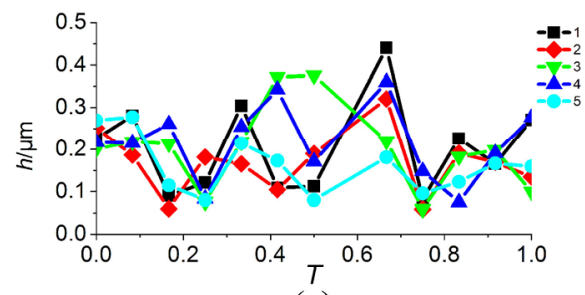

(a)

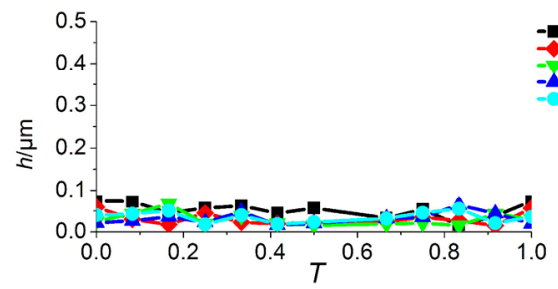

(c)

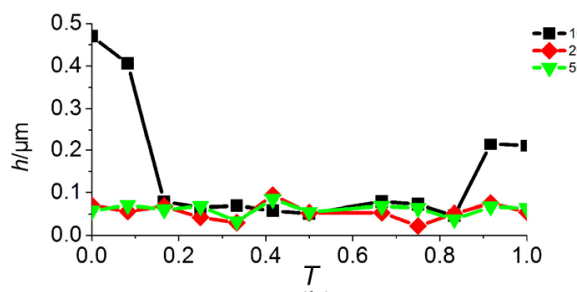

(b)

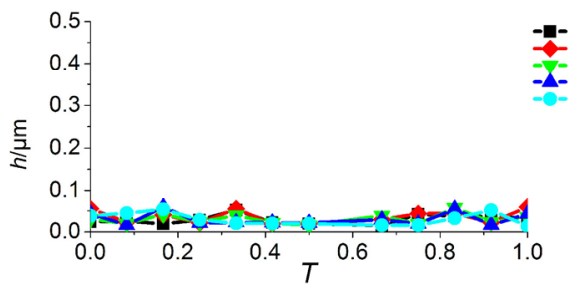

(d)

Fig. 14 Variation of central film thickness in some typical working periods $\left(v_{\max }=0.01 \mathrm{~m} / \mathrm{s}, w=50 \mathrm{~N}, T=0.5 \mathrm{~s}, L=1.25 \mathrm{~mm}\right)$.

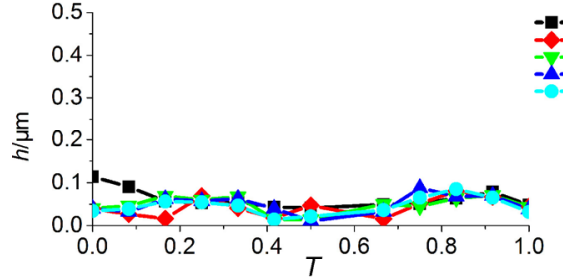

(a)

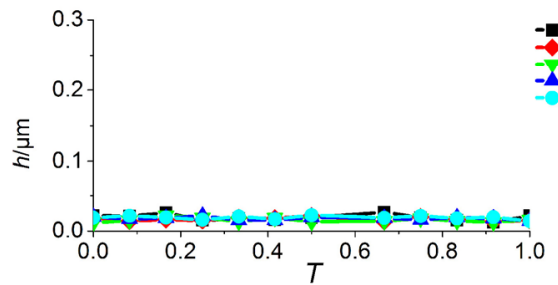

(c)

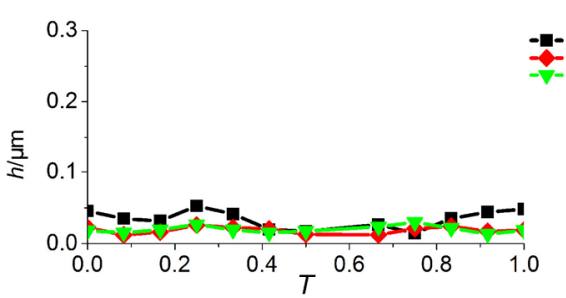

(b)

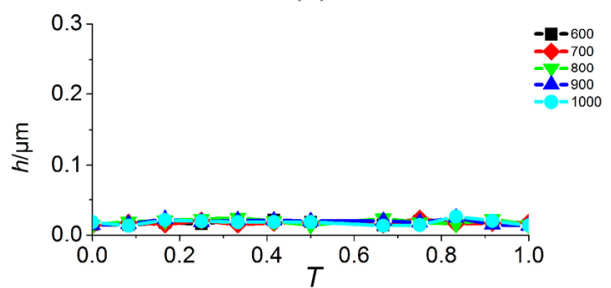

(d)

Fig. 15 Variation of minimum film thickness in some typical working periods $\left(v_{\max }=0.01 \mathrm{~m} / \mathrm{s}, w=50 \mathrm{~N}, T=0.5 \mathrm{~s}, L=1.25 \mathrm{~mm}\right)$.

first cycle was around $0.1 \mu \mathrm{m}$ and did not change as significantly as the central film thickness. In the first 10 cycles, there were small fluctuations, and they did not change much during the first 20 cycles. After 20 cycles, the trend was horizontal with a value of around $20 \mathrm{~nm}$, no longer governed by the variation of the entraining speed.

Figure 16 shows the optical interference image and the midsection thickness profiles for the first working cycle with $v_{\max }=0.01 \mathrm{~m} / \mathrm{s}, w=50 \mathrm{~N}, T=0.3 \mathrm{~s}$, and $L=$ $0.75 \mathrm{~mm}$. A load of $50 \mathrm{~N}$ produced a Hertzian contact diameter of $0.4 \mathrm{~mm}$, which was about half of the stroke length. In the first three figures, there are several thickener fiber clusters in the contact, resembling the steady-state optical images in Fig. 4 . The average film thickness was around $0.2 \mu \mathrm{m}$.

In Figs. 16(d) and 16(e), several circular heaps are formed, causing considerable fluctuations in the film thickness. However, around the stroke end (1/2T) in Figs. 16(f)-16(h), the aggregations of thickener fiber become fewer and scattered, and the average film thickness was around $0.1 \mu \mathrm{m}$. It is seen that in Figs. 16(k) and $16(1)$, there are considerable conglomerations of thickener fiber.

Figure 17 gives the results for the 1,000th cycle. The previous aggregations of the thickener fiber spread out, covering a larger area in the contact zone. Therefore, the film thickness was not reduced much. The average film thickness was around $0.1 \mu \mathrm{m}$, higher than that for $L=1.25 \mathrm{~mm}$. However, around the stroke 


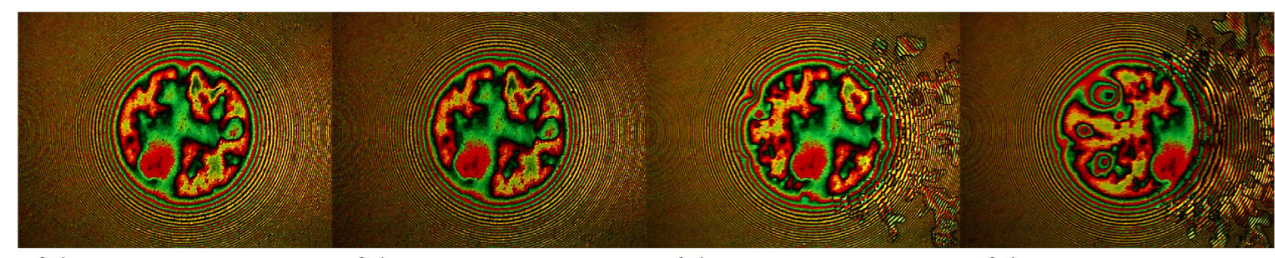

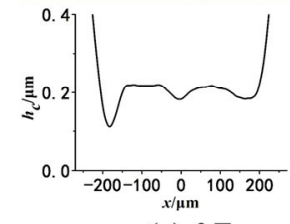

(a) $0 T$

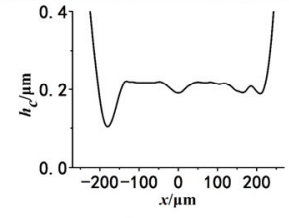

(b) $1 / 12 T$

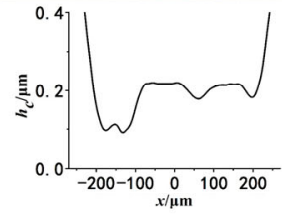

(c) $1 / 6 T$

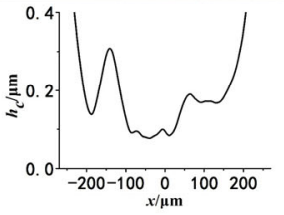

(d) $1 / 4 T$

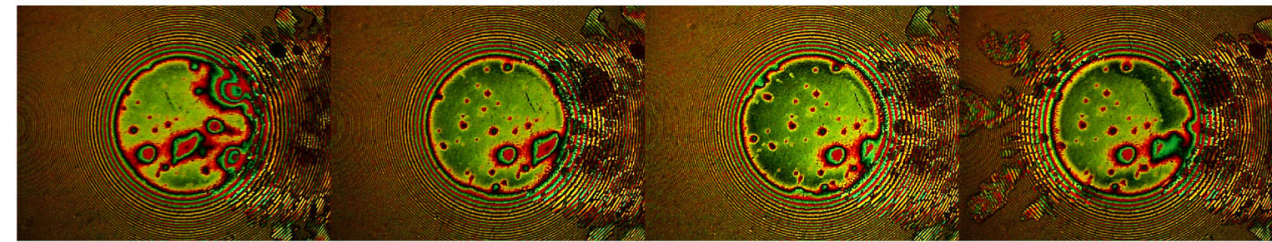

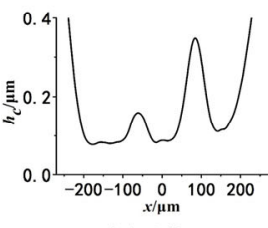

(e) $1 / 3 T$

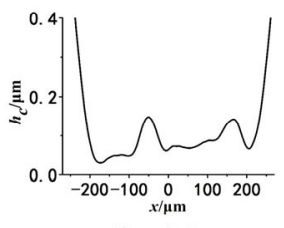

(f) $5 / 12 T$

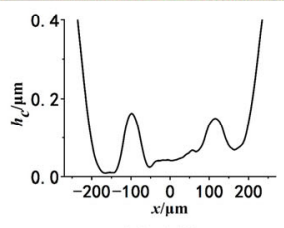

(g) $1 / 2 T$

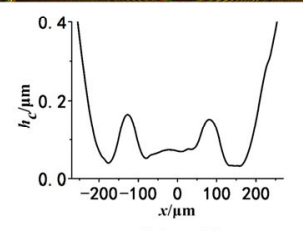

(h) $5 / 8 T$

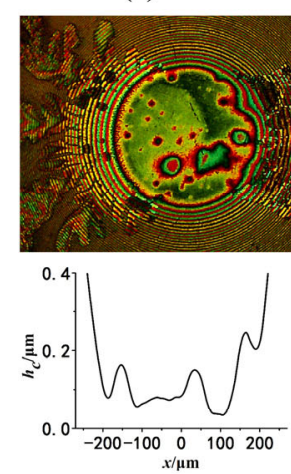

(i) $3 / 4 T$

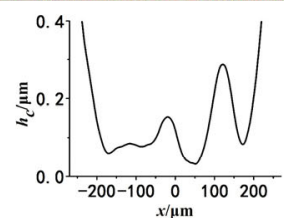

(j) $5 / 6 \mathrm{~T}$

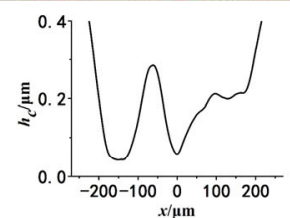

(k) $11 / 12 T$

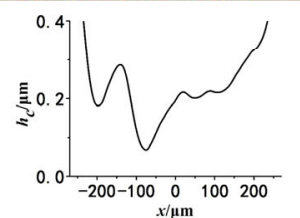

(l) $1 T$

Fig. 16 Interferograms and midsection film thickness during 1 st cycle under pure rolling reciprocating $\operatorname{motion}\left(v_{\max }=0.01 \mathrm{~m} / \mathrm{s}, w=50 \mathrm{~N}\right.$, $T=0.3 \mathrm{~s}, L=0.75 \mathrm{~mm})$.

end (Figs. 17(f)-17(h)), very little flattened thickener fiber remained, and the film thickness was thinner. This is because in the first cycle (Figs. 16(f)-16(h)), there was little thickener fiber in the contact.

Figure 18 shows the central film thickness for $v_{\max }=$ $0.01 \mathrm{~m} / \mathrm{s}, w=50 \mathrm{~N}, T=0.3 \mathrm{~s}$, and $L=0.75 \mathrm{~mm}$. In Fig. 18(a), for the first five cycles, although there are fluctuations, for each curve at around $0 T$ (or 1T), the central film thickness was the largest. By contrast, at around $1 / 2 T$, the central film thickness was smallest. This feature is different from the variation over one cycle with $L=1.25 \mathrm{~mm}$.
With an increase in the working cycle, the central film thickness around $0 T$ (or $1 T$ ) was reduced, while around $1 / 2 T$, it decreased and then increased again. During the 1,000th cycle, the fluctuation still existed. The valley shape does not change over 1,000 cycles. Figure 19 shows the minimum film thickness. The variation in the minimum film thickness was not as drastic as that of the central film thickness, and from the 5 th cycle, it became a straight line over the cycle.

Figure 20 provides the optical interferograms and the midsection thickness profiles for the 1st cycle for 


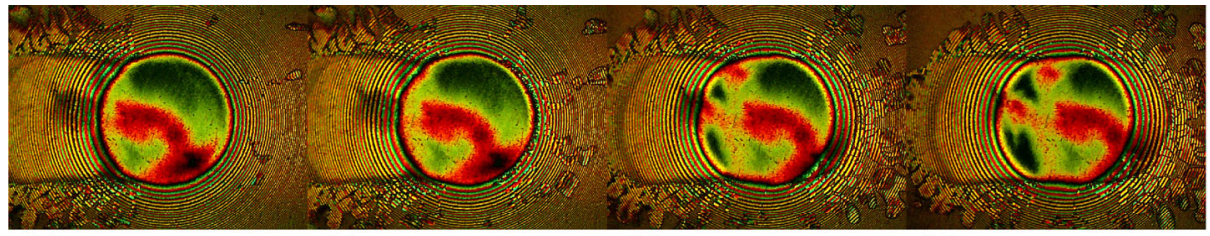

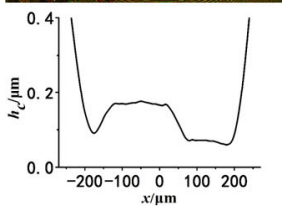

(a) $0 T$

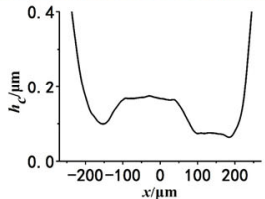

(b) $1 / 12 T$

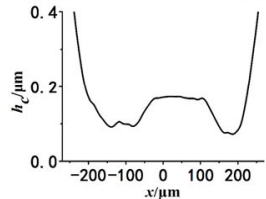

(c) $1 / 6 T$

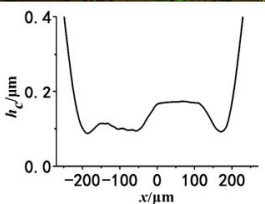

(d) $1 / 4 T$

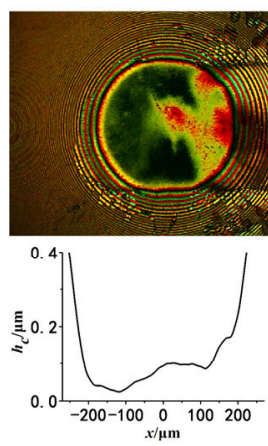

(e) $1 / 3 T$
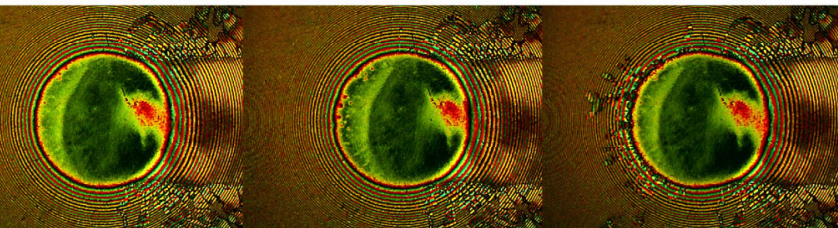

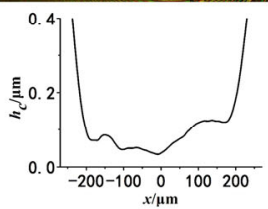

(f) $5 / 12 T$

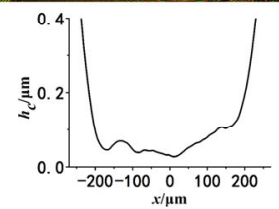

(g) $1 / 2 T$

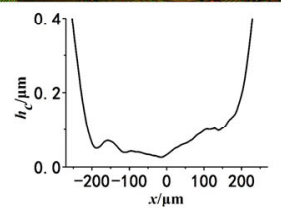

(h) $5 / 8 T$

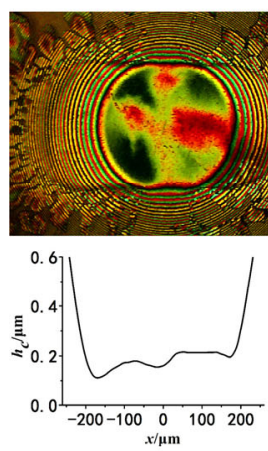

(i) $3 / 4 T$

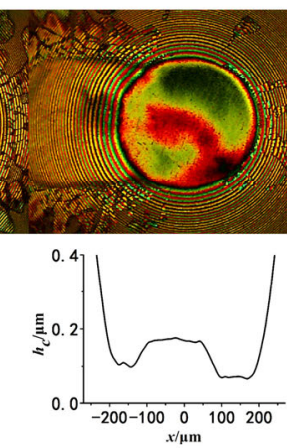

(j) $5 / 6 T$

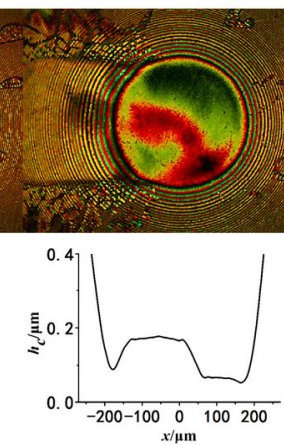

(k) $11 / 12 T$
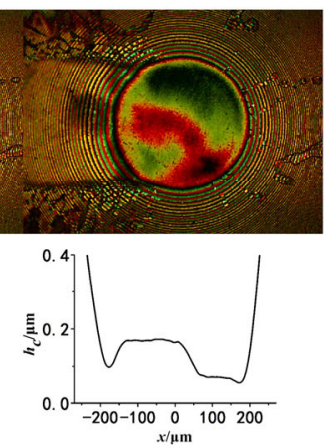

(1) $1 T$

Fig. 17 Interferograms and midsection film thickness during 1,000 th cycle under pure rolling reciprocating motion $\left(v_{\max }=0.01 \mathrm{~m} / \mathrm{s}\right.$, $w=50 \mathrm{~N}, T=0.3 \mathrm{~s}, L=0.75 \mathrm{~mm})$.

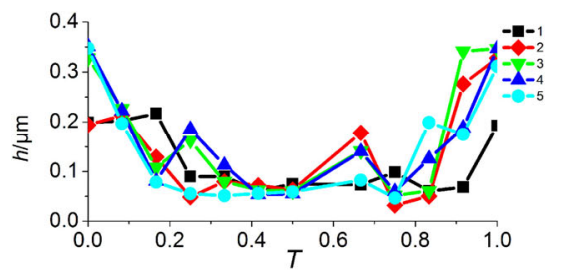

(a)

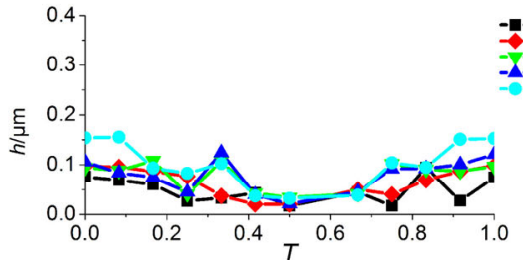

(c)

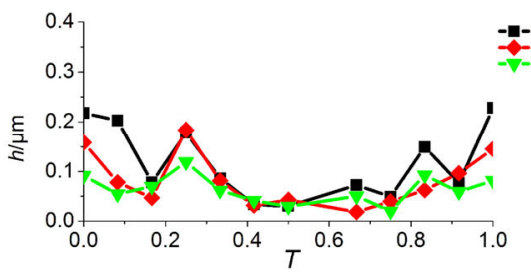

(b)

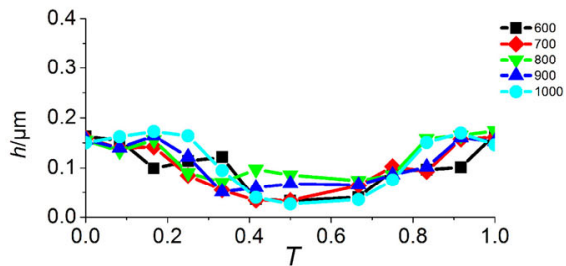

(d)

Fig. 18 Variation of central film thickness in some typical working periods ( $\left.v_{\max }=0.01 \mathrm{~m} / \mathrm{s}, w=50 \mathrm{~N}, T=0.3 \mathrm{~s}, L=0.75 \mathrm{~mm}\right)$. 


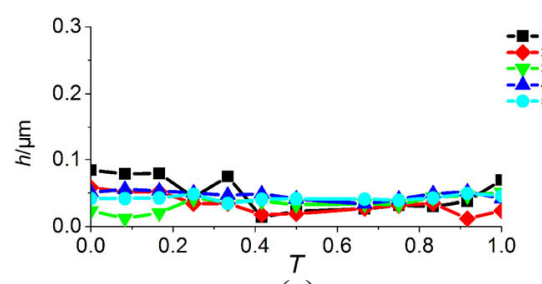

(a)

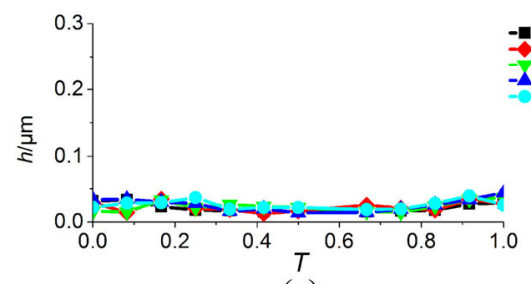

(c)

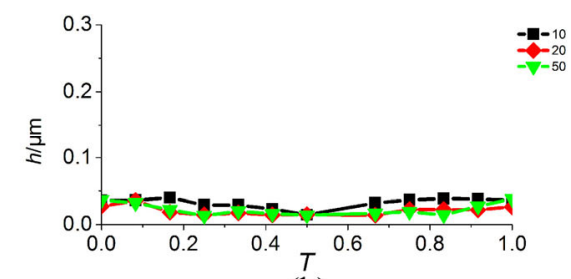

(b)

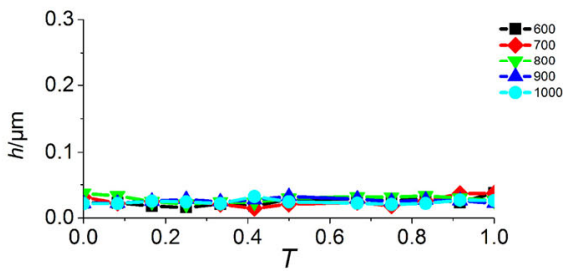

(d)

Fig. 19 Variation of minimum film thickness in some typical working periods $\left(v_{\max }=0.01 \mathrm{~m} / \mathrm{s}, w=50 \mathrm{~N}, T=0.3 \mathrm{~s}, L=0.75 \mathrm{~mm}\right)$.

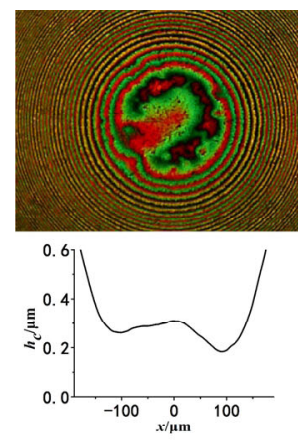

(a) $0 T$

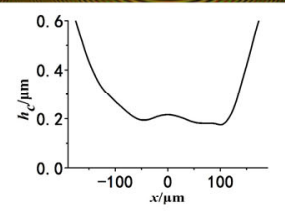

(b) $1 / 12 T$

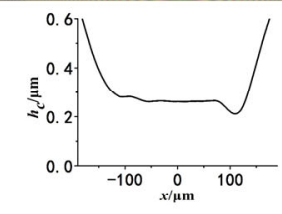

(c) $1 / 6 \mathrm{~T}$

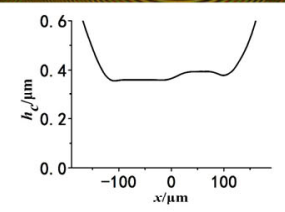

(d) $1 / 4 T$

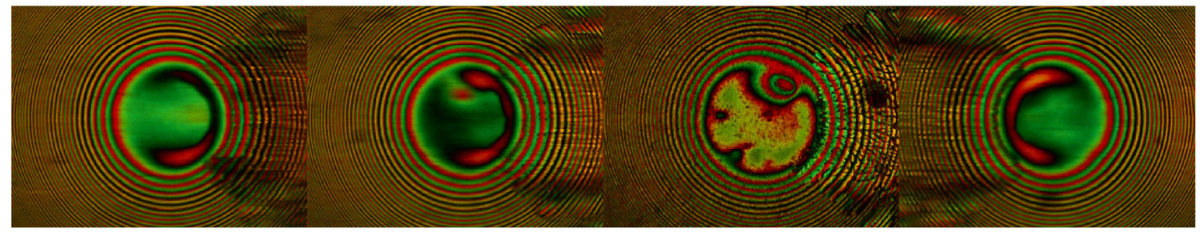

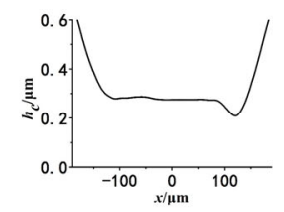

(e) $1 / 3 T$

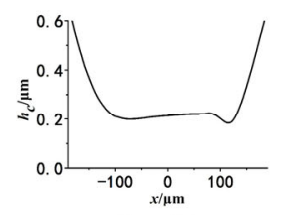

(f) $5 / 12 \mathrm{~T}$

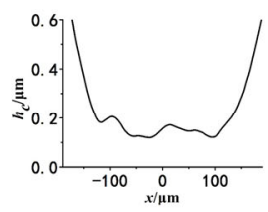

(g) $1 / 2 T$

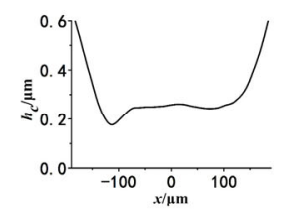

(h) $2 / 3 \mathrm{I}$

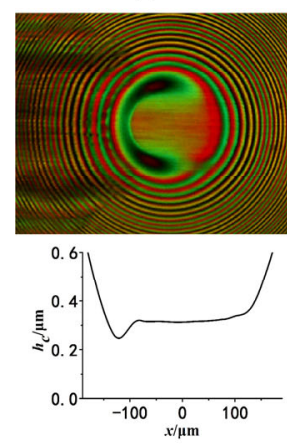

(i) $3 / 4 \mathrm{~T}$

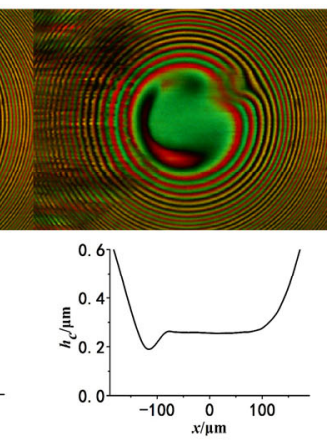

(j) $5 / 6 \mathrm{~T}$

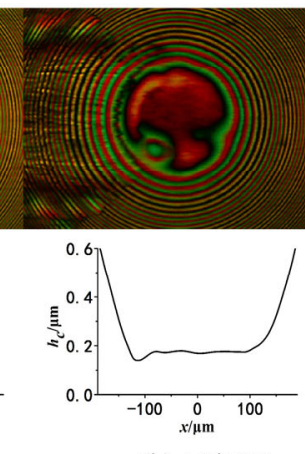

(k) $11 / 12 T$

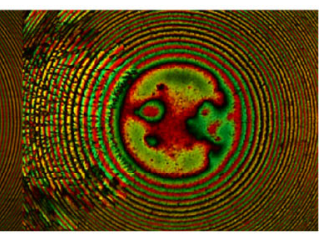

Fig. 20 Interferograms and midsection film thickness during 1 st cycle under pure rolling reciprocating motion $\left(v_{\max }=0.1 \mathrm{~m} / \mathrm{s}, w=15 \mathrm{~N}\right.$, $T=0.5 \mathrm{~s}, L=12.5 \mathrm{~mm})$. 
$v_{\max }=0.1 \mathrm{~m} / \mathrm{s}, w=15 \mathrm{~N}, T=0.5 \mathrm{~s}$, and $L=12.5 \mathrm{~mm}$. From Fig. 2, it is seen that the entraining speed $v_{\max }=$ $0.1 \mathrm{~m} / \mathrm{s}$ is at the right of the bottom of the V-shape. That is, under a steady state with an entraining velocity of $0.1 \mathrm{~m} / \mathrm{s}$, the thickener fiber did not influence the film thickness distribution. At the stroke ends (Figs. 20(a), 20(g), and 20(l)) or close to the stroke ends (Figs. 20(b) and $20(\mathrm{k}))$, there was thickener fiber in the contact, and the midsection film thickness showed a fluctuation.

In the other optical images, a typical EHL film shape is seen and the midsection film thickness is very smooth.
Figure 21 shows the results for the 200th cycle, it is seen that the film thickness in the contacts was reduced greatly by the severe starvation. Except for those around the stroke ends (Figs. 21(a), 21(b), 21(g), and 21(1)) in which there was a very small amount of scattered thickener fiber in the contact, bilateral scratches (indicated as white solid lines) of the glass surface appear in each image.

Figure 22 shows the contact area at the stroke center that was captured during the 300th cycle. The glass disc surface was damaged owing to the lack of effective

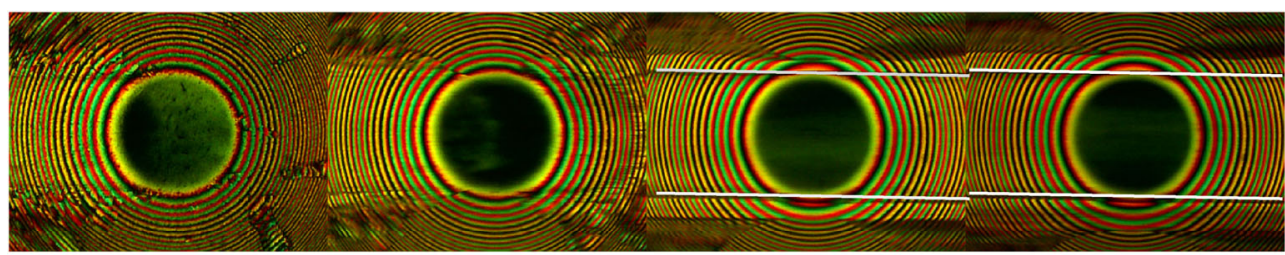

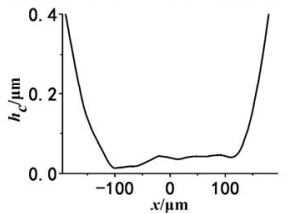

(a) $0 T$

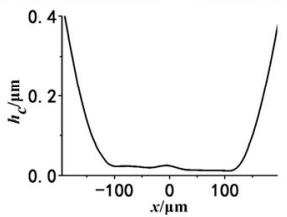

(b) $1 / 12 T$

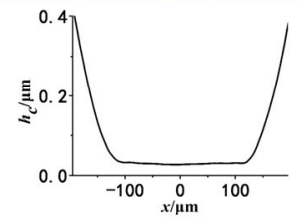

(c) $1 / 6 T$

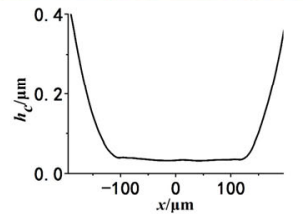

(d) $1 / 4 T$

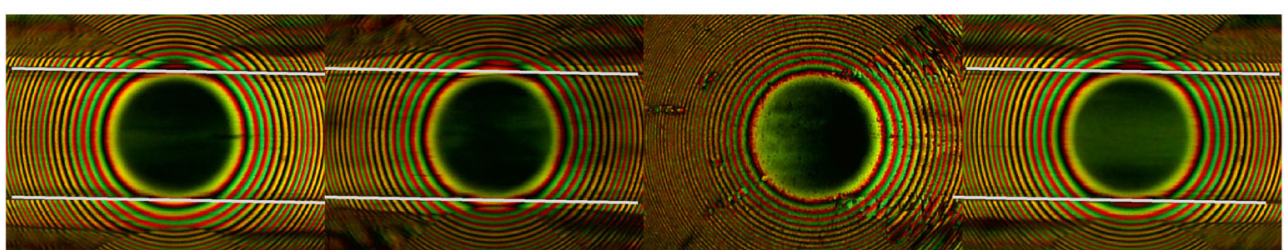

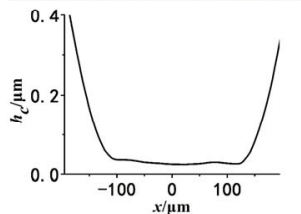

(e) $1 / 3 T$

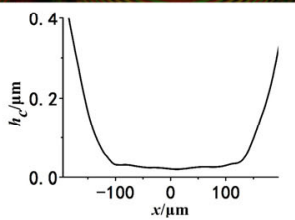

(f) $5 / 127$

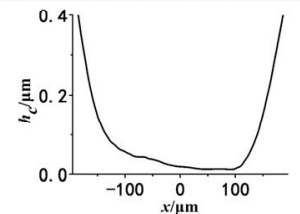

(g) $1 / 2 T$

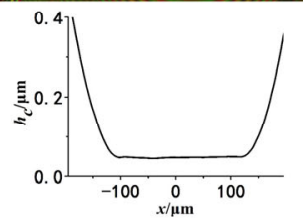

(h) $2 / 3 T$

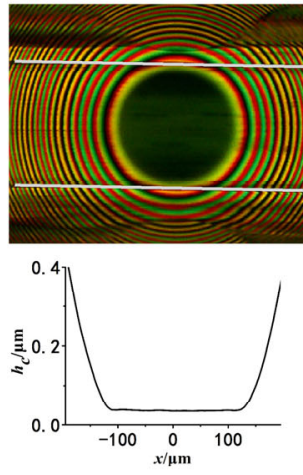

(i) $3 / 4 T$

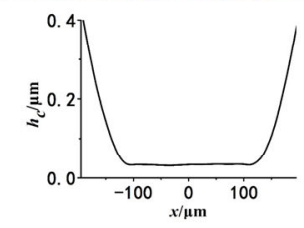

(j) $5 / 6 T$

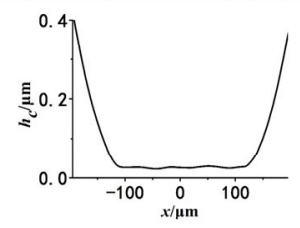

(k) $11 / 12 T$
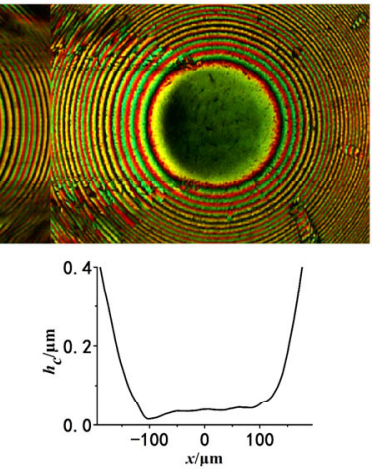

(1) $1 T$

Fig. 21 Interferograms and midsection film thickness during 200th cycle under pure rolling reciprocating $\operatorname{motion}\left(v_{\max }=0.1 \mathrm{~m} / \mathrm{s}, w=\right.$ $15 \mathrm{~N}, T=0.5 \mathrm{~s}, L=12.5 \mathrm{~mm})$. 


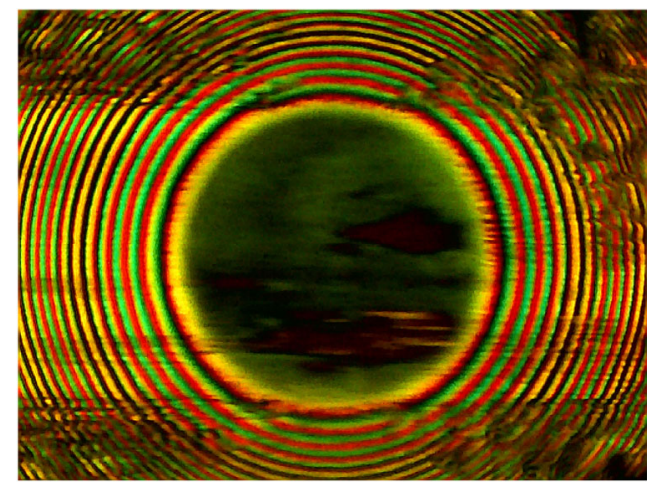

Fig. 22 Interferograms and scratches of glass disk after 300th cycle under pure rolling reciprocating motion (Centoplex 3, $v_{\max }=$ $0.1 \mathrm{~m} / \mathrm{s}, w=15 \mathrm{~N}, T=0.5 \mathrm{~s}, L=12.5 \mathrm{~mm})$.

lubrication. Figures 20-22 demonstrate that at the near right of the V-shape bottom, grease lubrication under reciprocating motion was detrimental to the surfaces.

Experiments were also conducted for grease Centoplex 2EP with maximum entraining speeds of $0.001 \mathrm{~m} / \mathrm{s}, 0.002 \mathrm{~m} / \mathrm{s}$, and $0.003 \mathrm{~m} / \mathrm{s}$ in a pure rolling reciprocating motion. All three entraining speeds are at the left side of the bottom speed of the V-shape. Since the entraining speeds were very low, the contact was full of thickener fiber at the beginning of the motion, but with an increase in the working period, the removal and replenishment of the thickener fiber happen at the same time but the removal was predominant.

After 1,000 working periods, around the stroke center, the majority of the thickener fiber was removed from the contact, but the starvation was not severe because of the very low entraining speed. Moreover, around the stroke end, much of the thickener fiber was pushed out of the contact, while the remained amount was bulldozed, as in Figs. 17(a)-17(d).

Experiments for Centoplex 2EP with a maximum entraining speed of $0.04 \mathrm{~m} / \mathrm{s}$ showed that at 100 working periods, a patch of the Cr-layer on the glass disk surface was removed at the stroke center (shown as a black spot in Fig. 23).

For both Centoplex 3 and Centoplex 2EP, it is seen that the transient behavior was different from that under steady-state conditions. Moreover, at the right of the V-shape bottom, the grease lubrication could damage the contact surfaces because less thickener fiber can enter the contact. Since the only added factor

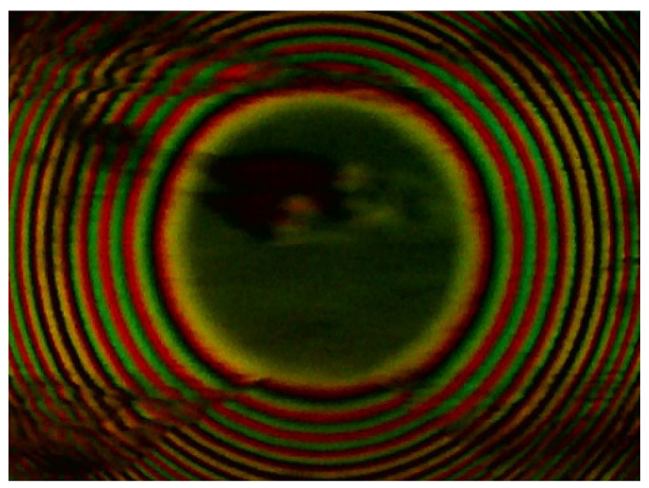

Fig. 23 Interferograms and scratch of glass disk at 100th cycle under pure rolling reciprocating motion (Centoplex 2EP, $v_{\max }=$ $0.04 \mathrm{~m} / \mathrm{s}, w=15 \mathrm{~N}, T=0.5 \mathrm{~s}, L=5 \mathrm{~mm})$.

was the transient velocity, i.e., the acceleration, the authors assume that the acceleration was responsible for the behavior under a reciprocating motion. Experiments will be carried out to clarify this mechanism in the future.

\section{Conclusions}

In this study, the variations of EHL contacts filled with grease thickener fiber in a pure rolling reciprocating motion were explored by using the optical interferometric technique. The transient results were compared with the results for a pure rolling steady-state condition. The effects of the stroke length and maximum entraining speed were also investigated. The conclusions are summarized as follows:

(1) At a low entraining speed, the contact is conglomerated with thickener fiber. Under a steady state, the lubrication state as well as the aggregation amount of the thickener fiber in the contact barely changes over long working hours. For reciprocating motions, the grease film thickness is the thickest at the stroke ends.

With an increase in the number of working cycles, the thickener fiber is gradually removed from the contact, grease starvation occurs, and the film thickness is subsequently reduced. After several hundreds of working cycles, the central and minimum film thicknesses fall and become horizontal, regardless of the variation of the entraining velocity. The actual life of the grease lubrication under a reciprocating condition is far below that of the steady-state condition. 
(2) The effect of the load in a steady-state condition simply increases the contact area to accommodate more fiber. The actual life of the grease lubrication in a reciprocating motion decreases with an increase in the applied load.

(3) With the same load and maximum entraining speed, the shorter the stroke length, the longer the actual life of the grease lubrication. With a shorter stroke length, after 1,000 working cycles, the thickener fiber is spread out in the contact instead of being removed.

(4) For both types of grease, a maximum entraining speed to the right of the lowest point of the V-shape is chosen to carry out the experiment. It is seen that under this condition, only around the stroke end, the contact is filled with thickener fiber in small working cycles, and very severe starvation occurs rapidly, causing surface scratches on the glass disk. The results demonstrate that around the near right of the bottom of the V-shape, grease lubrication under a reciprocating motion is detrimental to the surfaces.

\section{Acknowledgements}

This work was supported by the National Natural Science Foundation of China through grants No. 51875298 and No. 51275253.

Open Access: The articles published in this journal are distributed under the terms of the Creative Commons Attribution 4.0 International License (http:// creativecommons.org/licenses/by/4.0/), which permits unrestricted use, distribution, and reproduction in any medium, provided you give appropriate credit to the original author(s) and the source, provide a link to the Creative Commons license, and indicate if changes were made.

\section{References}

[1] Petrousevitch A I, Kodnir D S, Salukvadze R G, Bakashvili D L, Schwarzman V S. The investigation of oil film thickness in lubricated ball-race rolling contact. Wear 19(4): 369-389 (1972)

[2] Hooke C J. The minimum film thickness in lubricated line contacts during a reversal of entrainment-general solution and the development of a design chart. Proc Inst Mech Eng Part J J Eng Tribol 208(1): 53-64 (1994)

[3] Sugimura J, Jones W R, Spikes H A. EHD film thickness in non-steady state contacts. $J$ Tribol 120(3): 442-452 (1998)

[4] Wang J, Kaneta M, Yang P. Numerical analysis of TEHL line contact problem under reciprocating motion. Tribol Int 38(2): 165-178 (2005)

[5] Wang J, Hashimoto T, Nishikawa H, Kaneta M. Pure rolling elastohydrodynamic lubrication of short stroke reciprocating motion. Tribol Int 38(11-12): 1013-1021 (2005)

[6] Izumi N, Tanaka S, Ichimaru K, Morita T. Observation and numerical simulation of oil-film formation under reciprocating rolling point contact. Tribol Ser, 43: 565-572 (2003)

[7] Li G, Zhang C H, Luo J B, Liu S H, Xie G X, Lu X C. Film-forming characteristics of grease in point contact under swaying motions. Tribol Lett 35(1): 57-65 (2009)

[8] Li G, Zhang C H, Xu H Y, Luo J B, Liu S H. The film behaviors of grease in point contact during microoscillation. Tribol Lett 38(3): 259-266 (2010)

[9] Wang J, Meng X H, Wang S S, Zou Q. Grease film variation in reciprocating sliding motion. Tribol Int 114: 373-388 (2017)

[10] Ali F, Křupka I, Hartl M. Enhancing the parameters of starved EHL point conjunctions by artificially induced replenishment. Tribol Int 66: 134-142 (2013)

[11] Huang L, Guo D, Wen S Z, Wan G T Y. Effects of slide/roll ratio on the behaviours of grease reservoir and film thickness of point contact. Tribol Lett 54(3): 263-271 (2014)

[12] Eriksson P, Wikström V, Larsson R. Grease passing through an elastohydrodynamic contact under pure rolling conditions. Proc Inst Mech Eng J Eng Tribol 214: 309-316 (2000)

[13] Cann P M, Spikes H A. In lubro studies of lubricants in EHD contacts using FTIR absorption spectroscopy. Tribol Trans 34(2): 248-256 (1991)

[14] Cyriac F, Lugt P M, Bosman R, Venner C H. Impact of water on EHL film thickness of lubricating greases in rolling point contacts. Tribol Lett 61(3): 23 (2016)

[15] Zhang Y M. Studies on lubrication properties of lithium based grease. Master's thesis. Qingdao (China): Qingdao University of Technology, 2015.

[16] De Laurentis N, Kadiric A, Lugt P, Cann P. The influence of bearing grease composition on friction in rolling/sliding concentrated contacts. Tribol Int 94: 624-632 (2016)

[17] Kanazawa Y, Sayles R S, Kadiric A. Film formation and friction in grease lubricated rolling-sliding non-conformal contacts. Tribol Int 109: 505-518 (2017)

[18] Liu H C, Guo F, Guo L, Wong P L. A dichromatic interference intensity modulation approach to measurement of lubricating film thickness. Tribol Lett 58(1): 15 (2015) 


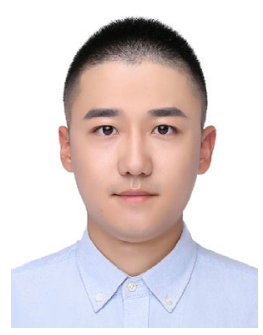

Yiming HAN. He received his bachelor degree in School of Mechanical Engineering in 2016 from Qingdao University of Technology, Qingdao,

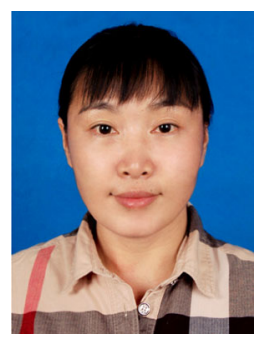

Jing WANG. She received her master degree from Qingdao University of Technology, China, in 2001 and Ph.D in Kyushu Institute of Technology, Japan, in 2006. She went back to work in Tribology Laboratory at Qingdao University of Technology
China. Now he is a Ph.D student in Tribology Laboratory at the same university. His research interests include grease lubrication and fretting.

at the end of 2006. She is now a professor of tribology with research interests covering fundamentals of lubrication theory, tribological applications in chain drives, cam-tappet mechanism and rolling element bearings, grease lubrication, impact wear and fretting. 